\title{
La Russie dans la presse des émigrés : Altona, Hambourg, Brunswick et Saint-Pétersbourg ${ }^{1 *}$
}

\author{
Vladimir A. Somov \\ Conservatoire national de Saint-Pétersbourg \\ vladimiralsomov@gmail.com
}

\section{Резюме}

Статья посвящена образу России, сложившемуся на страницах эмигрантской периодики, которая издавалась на Севере Европы: в Альтоне (Journal d'Altona, 1795), в Гамбурге (Le Spectateur du Nord, 1797-1802; Journal littéraire et bibliographique, 1799-1802; Le Réveil, 1798-1799; Le Censeur, 180o), Брауншвейге (L'Abeille, 1795; Mercure de France, 1800-1802). Издатель большинства этих журналов Пьер Франсуа Фош выполнял политические поручения роялистов, имел прочные связи с русским книжным рынком, неоднократно посещал Россию. Сами сотрудники были хорошо осведомлены о русских делах, некоторые из них жили в Петербурге. Журналы имели и русских корреспондентов. Редактор Le Spectateur du Nord Амабль де Бодюс привлек к сотрудничеству Н.М. Карамзина. "Русские" публикации отражают общее направление эмигрантских жкурналов: политика, литература, французская книжность. Они демонстрируют симпатии их авторов к России, которая изображается как держава способная восстановить порядок во Франции и в Европе. Русские власти осуществляют контроль за эмигрантскими журналами, за тем, какой образ России представлен на их страницах. В самой Российской империи издаются эмигрантский Journal littéraire de Saint-Pétersbourg (1798-180о) и официозный Journal du Nord (1807-1812), направленный против наполеоновской пропаганды, в котором сотрудничают те же самые французы. Все эти издания адресованы как эмигрантам, так и местным элитам. Эмигранты, благодаря широкому распространению французского языка, благодаря французской книготорговле прочно установленной в Европе и своей литературной деятельности, становятся посредниками в отношениях между странами, в процессе взаимодействия европейских культур.

Mots clé

émigrés ; presse en langue française ; Allemagne ; Russie ; Le Spectateur du Nord ; Amable de Baudus, Nicolas Karamzine ; Pierre François Fauche

A l'époque de la Révolution, l'empire de Russie donne à de nombreux nobles français l'espoir de retrouver bonheur et prospérité et devient un lieu de refuge dans leurs errances. Les émigrés considèrent l'empire comme une puissance susceptible de rétablir l'ordre en France et en Europe. Ils ont besoin de soutien financier, et ils font sans cesse appel à Catherine II pour obtenir des subventions. Et l'impératrice, qui ne se mêle pas des actions militaires contre la France, verse des sommes considérables, accueille les émigrés dans ses États, accorde des postes importants à quelques Français. Ses successeurs, Paul $\mathrm{I}^{\mathrm{er}}$ et Alexandre $\mathrm{I}^{\mathrm{er}}$, restent également très accueillants à l'égard des émigrés. La route des

\footnotetext{
* Cette étude a reçu le soutien de la Herzog August Bibliothek à Wolfenbüttel et de la fondation Maison des sciences de l'homme à Paris. Je tiens à remercier pour leurs conseils mes collègues : Gillian Bepler, Gabriele Ball, Michael Schippan (Wolfenbüttel), Peter Albrecht (Brunswick), Konstantin Shorokhov, Sergueï Korolev (Saint-Pétersbourg), Sergueï Karp, Kumar Guha, Vladislav Rjéoutski (Moscou), Florence de Baudus, Sonia Colpart (Paris), Georges Dulac (Montpellier).
} 
Français qui partent pour la Russie passe souvent par l'Allemagne. Pour leur part, les pays allemands connaissent également un afflux extraordinaire de réfugiés ${ }^{2}$.

Cet article porte sur la presse des émigrés au Nord de l'Europe - en Altona (le Royaume Danois), en Allemagne, dans la ville de Hambourg et dans le duché de Brunswick, - et à Saint-Pétersbourg, et tout particulièrement sur l'image de la Russie dans ces périodiques.

La ville de Hambourg, libre et riche, grand port maritime où, depuis longtemps, séjournaient de nombreux étrangers, est alors une plaque tournante de la diplomatie où l'on peut rencontrer des représentants de nombreuses puissances européenne. La presse hambourgeoise a une importance internationale ${ }^{3}$. Le duché de Brunswick, pour sa part, accueille des centaines d'émigrés. Ici, les royalistes sont très soutenus par le duc Karl Wilhelm Ferdinand, un francophile confirmé et une personnalité des plus éminentes de la Contre-Révolution ${ }^{4}$. Louis XVIII, le roi en exil, a trouvé refuge à Blankenburg, dans les domaines du duc de Brunswick, avant de s'installer en Russie, à Mitau (Jelgava), dans le château des anciens grands-ducs de Courlande. A cette époque, les royalistes, les autorités de Brunswick et de Saint-Pétersbourg constituent un réseau politique international orienté contre la France républicaine.

De nombreux réfugiés ont le goût des lettres, certains ont l'expérience d'une activité littéraire. Ils ont besoin de leur presse à eux pour réunir le monde dispersé de l'émigration. Plusieurs périodiques français sont lancés alors au Nord de l'Europe: L'Abeille (1795), Journal d'Altona (1795), Le Spectateur du Nord (1797-1802), Journal littéraire et bibliographique (1799-1802), Le Réveil (1798-1799), Le Censeur (1800). Ces éditions sont actuellement dispersées à travers toute l'Europe, certaines sont presque introuvables dans leur intégralité, comme le Journal d'Altona, dont la série complète est devenue accessible seulement récemment ${ }^{5}$.

Ces périodiques francophones soi-disant «allemands » traitent régulièrement des questions russes, plusieurs journalistes sont liés à la Russie, où dans les années 1798-1800, paraît également un périodique publié par un émigré, le chevalier de Gaston, le Journal

\footnotetext{
${ }^{2}$ Fernand Baldensperger, Le mouvement des idées dans l'émigration française (1785-1815), Paris, 1924, t. 1, p. 160-167 ; Ghislain de Diesbach, Histoire de l'émigration, 1789-1814, Paris, 2007, p. 299-376 ; Thomas Höpel, Emigranten der Französichen Revolution in Preussen 1789-1806. Eine Studie in vergleichender Perspective. Leipziger Universität Verlag 2000 (Deutsch-Französische Kulturbibliothek, Band 17) ; Elisabeth Kruse, Die Emigranten in der Französischen Revolution in Kurhannover. Hannover, 1990; Sabine Diezinger, Französische Emigranten und Flüchtlinge in der Margrafschaft Baden (1789-180o), Frankfurt am Main: Peter Lang, 1991 (Europäische Hochschulschriften Reihe III Geschichte und ihre Hilfswissenschaften, Bd. 500), etc.

3 Sur les émigrés français à Hambourg voir Fernand Baldensperger, Le mouvement des idées dans l'émigration française (1785-1815), Paris, 1924, t. 1, p. 160-167 ; Maike Manske, Möglichkeiten und Grenzen des Kulturtransfers: Emigranten der Französischen Revolution in Hamburg, Bremen und Lübeck, Saarbrücken, 2008.

4 В.А. Сомов, «Брауншвейгская библиотека князя Дмитрия Алексеевича Голицина», История библиотек: Исследования, материалы, документы [V.A. Somov, «La bibliothèque du prince Dmitry Alekseevitch Golitsyn à Brunswick», Histoire des bibliothèques. Recherches et documents], SaintPétersbourg, Bibliothèque nationale de Russie, 200o, fasc. 3, p. 170-193; Peter Albrecht, « Das Zeitalter des aufgeklärten Absolutismus », Die Braunschweigische Landesgeschichte Jahrtausendrückblick einer Region. Hrsgb. von Horst-Rüdiger Jarck, Gerhard Schildt, Braunschweig, 2001, S. 575-610 ; Gillian Bepler, « Literatur und Buchkultur», Ibid., S. 611-628; Günter Scheel, «Die Emigranten der Französischen Revolution im Fürstentum Braunschweig-Wolfenbüttel », Braunschweigisches Jahrbuch für Landesgeschichte / Hrsgb. von Rüdiger Jarck, 2002, Bd. 83, S. 35-58.

${ }^{5}$ Deutsche Presse : biobibliographische Handbücher zur Geschichte der deutschsprachigen periodischen Presse von den Anfängen bis 1815, Holger Böning, Band 2 (Altona - Bergedorf - Harburg - Schiffbek Wandsbek), Stuttgart-Bad Cannstatt, Frommann-Holzboog, 1997, n¹23, p. 342. François Richard, Les écrits d'Amable de Baudus dans la presse : Le Journal d'Altona, [Saint-Maur], F. Richard, 2013.
} 
littéraire de Saint-Pétersbourg (1798-1800) ${ }^{6}$ et, au début du XIX ${ }^{\mathrm{e}}$ siècle, le Journal du Nord (1807-1812), un périodique officieux auquel collaborent plusieurs émigrés ${ }^{7}$.

La librairie française et la presse francophone sont présentes au XVIII ${ }^{\mathrm{e}}$ siècle en Allemagne, ainsi qu'en Russie, et ces imprimés ont une grande importance pour le transfert des idées et des savoirs dans ces pays ${ }^{8}$. A l'époque de la Révolution, la production et la diffusion des livres français sont stimulés par les émigrés. Vers la fin du $\mathrm{XVIII}^{\mathrm{e}}$ siècle, la Russie devient un pays attrayant pour la librairie française. Le nombre de lecteurs francophones, issus de couches sociales diverses et non plus seulement de la haute noblesse, augmente, la demande en livres bon marché s'accroît. Mais, pendant le règne de Paul I ${ }^{\mathrm{er}}(1796-1801)$, la censure se fait lourdement sentir. Les pouvoirs tentent de surveiller surtout les livres français pour éviter l'influence de la Révolution et ce sont les ouvrages traitant d'événements politiques, les périodiques et les Russica, que l'on surveille en premier lieu. Cette politique censoriale va jusqu'à interdire complètement, au mois d'avril 1800, l'importation des ouvrages étrangers. Mais, malgré les persécutions de la censure, la librairie française en Russie réussit à subsister, grâce à une forte demande en livres en français dans la société russe et à l'afflux d'émigrés, et se rétablit très vite au début du règne d'Alexandre $\mathrm{I}^{\mathrm{er}}$.

$\mathrm{Au}$ Nord de l'Allemagne, les Français réfugiés ont à leur disposition plusieurs spécialistes expérimentés en production de livres français. La personnalité la plus importante de ce monde est Pierre François Fauche, libraire-imprimeur d'origine neuchâteloise. Avec son frère, Abraham-Louis Fauche-Borel ${ }^{9}$, ce grand meneur d'éditions a réussi à créer au Nord de l'Europe, y compris en Russie, un véritable réseau d'hommes des livres. L'activité des libraires Fauche, qui sont tous les deux des agents royalistes, comme celle de plusieurs autres émigrés, a une orientation politique ${ }^{10}$.

\footnotetext{
${ }^{6}$ Сводный каталог книг на иностранных языках, изданных в России в XVIII веке. 1701-180о, t. 4, Периодика, [Catalogue collectif des éditions en langues étrangères imprimées en Russie au XVIII siècle, t. 4, presse], Saint-Pétersbourg, 2004, p. 340-364.

${ }^{7}$ В.А. Сомов, «Россия на страницах французских эмигрантских журналов конца XVIII в. (Гамбург, Брауншвейг, Санкт-Петербург)», Немцы в России. Немецкий мир Санкт-Петербурга [Vladimir A. Somov, «La Russie à travers les journaux des émigrés français: Hambourg, Braunschweig, SaintPétersbourg », Die Deutschen in Russland. Die Deutsche Welt Sankt Petersburgs], sous la dir. de Dittmar Dahlmann et Galina Smagina, Saint-Pétersbourg, 2015, p. 371-384.

${ }^{8}$ Annett Volmer, Presse und Frankophonie im 18. Jahrhundert. Studien zur französischsprachigen Presse in Thüringen, Kursachsen und Rußland, Leipzig, Leipziger Universitätsverlag, 2000 ; Vladimir Somov, « La librairie française en Russie au XVIII ${ }^{\mathrm{e}}$ siècle ", Est-Ouest: Transferts et réceptions dans le monde du livre en Europe (XVII $-X X^{e}$ siècles), éd. par F. Barbier, Leipzig, Leipziger Univesitätsverlag, 2005, p. 89-107 ; Jeffrey Freedman, Books without borders in Enlightenment Europe: French Cosmopolitanism and German Literary Markets, Philadelphia: University of Pennsylvania Press, 2012.

9 Abraham-Louis Fauche-Borel, Mémoires, Paris, Moutardier, 18294 vol.; Idem, Précis historique des differentes missions dans lesquelles Louis Fauche Borel a été employé pour la cause de la monarchie, Paris, Aux frais de l'Auteur, 1815. Il faut noter que les contemporains, aussi bien que les chercheurs, confondent souvent les deux frères.

${ }^{10}$ Владимир А. Сомов, «Европейская книга на пути в Россию: французское книгоиздательство и книготорговля в Нижней Саксонии в конце XVIII в.», «Вводя нравы и обычаи Европейские в Европейском народе»: К проблеме адаптации западных идей и практик в Российской империи, [Vladimir A. Somov, « Les livres européens en voie pour la Russie : l'édition et la librairie françaises en Basse Saxe à la fin du XVIII ${ }^{\mathrm{e}}$ siècle », "Introduire les mœurs et les coutumes européens chez un peuple européen": l'adaptation des idées et des pratiques occidentales dans l'empire de Russie], sous la dir. d'Andreï Doronine, Moscou, 2008, p. 236-251 ; Владимир А. Сомов, «Пьер Франсуа Фош - издатель полного собрания сочинений Вольтера ", Книжная старина: Сб. науч. трудов [Vladimir A. Somov, "Pierre François Fauche, éditeur des Euvres complètes de Voltaire », L'Antiquité livresque: Recueil des travaux scientifiques], fasc. 2, Saint-Pétersbourg, 2011, p. 165-174; Vladimir A. Somov « Pierre François Fauche,
} 
Fauche réside d'abord à Hambourg, puis il ouvre une librairie à Brunswick et ensuite acquiert une imprimerie dans cette ville. Son entreprise prend de l'importance pendant les années de la Révolution grâce à l'afflux d'émigrés. Parmi les livres produits par Fauche, il faut noter des réimpressions des éditions parisiennes, et des ouvrages d'émigrés éminents (Dumouriez, Lally-Tollendal, Mallet du Pan, madame de Genlis, Sénac de Meilhan, Rivarol, etc.). Pour son commerce il possède des dépôts en Allemagne (Hambourg, Brunswick, Leipzig), à Paris et à Londres.

La maison de Pierre François Fauche à Hambourg est alors un des principaux centres de l'émigration. D’après le récit de son frère, Fauche-Borel, c'était « le rendez-vous des émigrés et des gens des lettres. Le comte de Rivarol y venait travailler à son fameux Dictionnaire, et Mr. Baudus y composait le Spectateur du Nord qu'il rédigeait pour le compte de mon frère $»^{11}$.

\section{La presse des émigrés et la Russie}

\section{Journal d'Altona}

La rencontre de Pierre François Fauche avec Amable de Baudus s'est passée avant la création du Spectateur du Nord. Ce magistrat français, ancien avocat de Cahors contraint de quitter la France, rejoint en juillet l'armée des Princes, qui sera dissoute peu de temps après. Refugié en Hollande, il prête sa plume à la Gazette de Leyde, puis il va à Altona ${ }^{12}$. C'est dans cette petite ville située près de Hambourg, mais sous la domination du roi du Danemark, que Baudus lance le Journal d'Altona ou correspondance du Nord. Avec privilège de Sa Majesté Danoise ${ }^{13}$. Fauche s'occupe de la diffusion de ce journal en compagnie du libraire d'Altona Schwarzfeld. Le nouveau périodique est conçu comme un quotidien : «Ce Journal paroit tous les jours, excepté le Dimanche. On s'abonne pour Hambourg chez P. F. Fauche, Libraire ; pour Altona chez le Sr. Schwarzfeld, Pail-Mail N $34{ }{ }^{14}$. Le premier numéro est daté du $1^{\mathrm{er}}$ juillet 1795 .

Le Journal d'Altona contient des nouvelles politiques européennes, il raconte des événements de la France républicaine, ainsi que les activités des royalistes. Les actualités locales de cette ville maritime sont consacrées aux «cours des changes et des espèces », au " prix courant des marchandises », aux arrivées et aux départs des navires, etc. On fait la publicité des nouveaux livres produits et vendus par Fauche, on insère des annonces de Français à la recherche de leurs proches, de travail, de compagnons de voyages, etc.

La Russie est largement citée dans les actualités, notamment dans le dossier du partage de la Pologne. Les lettres de Varsovie, de Berlin, de Vienne informent de la politique de

l'imprimeur-libraire européen et ses catalogues ", Le livre entre le commerce et l'histoire des idées. Les catalogues de libraires ( $X V^{e}-X I X^{e}$ siècle), études réunies par Annie Charon, Claire Lesage et Ève Netchine, Paris, Ecole des chartes, 2011, p. 59-87 ; Jean Daniel Candaux, « Louis Fauche-Borel, imprimeur de la ContreRévolution (1791-1798) », Aspects du livre neuchâtelois : Etudes réunies à l'occasion du $450^{e}$ anniversaire de l'imprimerie neuchâteloise, Neuchâtel, 1986, p. 336-432.

${ }^{11}$ A.L. Fauche-Borel, Mémoires..., t. 2. p. 202.

${ }^{12}$ Paul Hazard, «Le Spectateur du Nord », Revue d'histoire littéraire de la France, 1906, p. 26-50 ; Florence de Baudus, Amable de Baudus, des services secrets de Talleyrand à la direction de la Censure sous Louis XVIII, Paris, Editions SPM, 2012.

${ }^{13}$ Chaque numéro du journal a une épigraphe latine « Unam dicendi laudem putant esse brevitatem, non exornatores rerum, sed tantum narratores. Ciceron » [La brièveté est le mérite qu'ils recherchent, ils ne doivent pas orner les faits, mais les raconter].

${ }^{14}$ Journal d'Altona, 1795, 1 juillet, $\mathrm{n}^{\circ}$ 1. Presque chaque cahier du journal contient cette annonce. 
Catherine II, de la présence des troupes russes. Au mois d'août on écrit : « Le Général russe de Tutolmin a publié le 18 du mois dernier, dans les Palatinats de Volhynie, de Chełm et de Belz occupés depuis peu par ses troupes, un Manifeste, par lequel il annonce aux habitants de ces Pays, qu'ils demeureront à jamais sujets de l'Empire de Russie ${ }^{15}$. Au mois de septembre on informe que les « nobles Polonois [...] qui ont des possessions dans l'Ukraine, doivent les vendre pour un juste prix à des sujets Russes ${ }^{16}$. Au mois d'octobre : «L'Impératrice de Russie voulant récompenser le zèle qu'ont montré ses Officiers Généraux dans la dernière campagne contre les Polonois, vient de leur distribuer, dans la Lituanie, une partie des possessions, appelées ci-devant Economies-Royales, ainsi que des biens appartenant à des Polonois émigrés, qui ont pris une part très active à la dernière révolution. S. M. I. a accordé plusieurs milliers de Paysans au Feld-Maréchal Comte de Suwarow, et a gratifié de même les autres Généraux et Commandans, en proportion de leurs grades et leurs services $\gg^{17}$.

Le journal ne cache pas les pertes des Polonais et le mécontentement de la population : «Sur les plaintes nombreuses, portées par les Habitans des Provinces contre les Cosaques Russes qui s'y livrent à divers excès, le Général de Buxhewden a donné des ordres sévères pour que ces Cosaques soient rigoureusement poursuivis et punis exemplairement ». On annonce que « le 4 du mois [de novembre] le Faubourg de Prague doit être illuminé, et le Feld-Maréchal Comte de Suwarow doit y donner un grand Bal, en mémoire de la prise de ce Faubourg emporté à pareil jour de l'année dernière. Cette Fête contrastera un peu avec la cérémonie funèbre, qui doit avoir lieu le même jour et le service solennel, qui doit être célébré pour les 20 mille personnes des deux sexes, qui périrent dans la journée mémorable du 4 Novembre $»^{18}$.

On apprend l'élargissement des frontières de l'Empire, par exemple au mois de juillet une lettre de Varsovie annonce que «des Duchés de Courlande et de Sémigalie et du District de Pliten [...] sont réunies à perpétuité à l'Empire Russe, que les Habitants doivent prêter serment de fidélité à l'Impératrice, et que le duc de Courlande, a renoncé pour lui et ses descendants à tous ses droits et prétentions sur les deux Duchés ${ }^{19}$.

La Russie est présentée dans le journal comme une puissance capable de se confronter à la France révolutionnaire. Les lettres de Copenhague, d'Altona, apportent des nouvelles sur le déplacement de la flotte russe : «Sa seule apparition a produit le bon effet de faire rentrer dans leurs ports, tous les Corsaires François, qui infestaient depuis quelque temps la Mer du Nord ${ }^{20}$. On écrit de Londres : «Nos nouveaux Alliés les Russes servent à protéger notre Commerce dans les Mers du Nord et à gêner celui de l'Ennemi. La Frégate le Prince Potemkine s'est emparée de 4 Navires Hollandois et d'un Corsaire François, sorti de Dunkerque $»^{21}$. On annonce une alliance politique entre la Russie et l'Angleterre, des contacts économiques entre l'Empire et les Provinces-Unies. Les lettres de Constantinople informent des différends entre «la Porte et la cour de SaintPétersbourg ".

Parmi les personnalités russes (les généraux, les diplomates, etc.) Alexandre Souvorov, qui a écrasé l'insurrection polonaise et qui s'est emparé de Varsovie, est mentionné le plus

\footnotetext{
${ }^{15}$ Journal d'Altona, 1795, 20 août, $\mathrm{n}^{\circ} 44$.

${ }^{16}$ Journal d'Altona, 1795, 7 septembre, $\mathrm{n}^{\circ} 59$.

${ }^{17}$ Journal d'Altona, 1795, 3 octobre, $\mathrm{n}^{\circ} 82$.

${ }^{18}$ Journal d'Altona, 1795, 12 novembre, $\mathrm{n}^{\circ} 116$.

${ }^{19}$ Journal d'Altona, 1795, 14 juillet, $\mathrm{n}^{\circ} 12$.

${ }^{20}$ Journal d'Altona, 1795, 10 juillet, $n^{\circ} 9 ; 16$ juillet, $n^{\circ} 14 ; 14$ août, $n^{\circ} 39$.

${ }^{21}$ Journal d'Altona, 1795, 23 novembre, $\mathrm{n}^{\circ} 125$.
} 
souvent. Ainsi, au mois de septembre on écrit : «Le Feld-Maréchal Comte de Suwarow n'est pas encore de retour de son voyage ; et l'on assure même qu'il a reçu ordre de se rapprocher sans aucun délai des frontières de la Russie, où des troubles, qui viennent d'éclater parmi les Cosaques du Don, rendent sa présence nécessaire. Plusieurs régimens de Chasseurs sont commandés pour marcher vers cette partie ${ }^{22}$. Dans le numéro suivant on désapprouve ces bruits : « Les lettres de la Pologne [...], loin de confirmer ce que nous avoient annoncé [...] sur les mouvemens des Cosaques du Don, et le rappel du comte de Suwarow vers cette partie de l'Empire Russe, nous apprennent que ce Général est de retour à Varsovie ${ }^{23}$.

Catherine II, dont les émigrés ont le soutien, reçoit une appréciation toujours favorable, même de la part du camp républicain. Ainsi, parmi « des nouvelles de Paris » on cite largement le rapport «sur la situation politique de l'Europe » fait à la Convention par François Antoine de Boissy d'Anglas.

Le passage le plus saillant du rapport, est peut-être celui, où Boissy parle de l'impératrice de Russie d'une manière très remarquable : "Cette Souveraine, dit-il, dont les projets ambitieux, la politique raffinée et le caractère altier sont assez connus, ne peut servir de bonne-foi ses Alliés. Catherine ambitionne tous les genres de gloire. Longtemps elle étonna l'Europe en réunissant sur le trône la philosophie et la force ; Elle puisa dans Montesquieu les principes de son code; Elle convertit en lois plusieurs pages de D’Alembert ; Catherine ne peut avoir une véritable haine contre une Nation, qui a mis en pratique cette philosophie qu'elle a chérie elle-même. La France peut lui offrir un appui contre les Puissances d'Allemagne, qui, en se réunissant contre elle, pourroient la repousser dans les glaces du Nord. - Catherine a excité par des promesses les Membres de la coalition. Constante dans le projet d'abaisser le Croissant, elle veut avoir le champ libre pour marcher à Constantinople, et Elle fait tous ses efforts pour reculer une pacification qu'elle redoute"24.

A ceux qui s'intéressent à la personne de l'impératrice, Fauche propose « un petit nombre d'exemplaires de l'Estampe de Catherine II, Impératrice des Russies, en pied, gravée par Walker, d'après Lampi en manière angloise. Le prix est de $40 \mathrm{mk}$. courants ${ }^{25}$.

A Altona on reçoit des nouvelles de la vie de la cour russe. Au mois de novembre on informe que la Princesse de Saxe-Cobourg est arrivée à Saint-Pétersbourg «avec les 3 Princesses ses Filles » et que « c'est la plus jeune des trois Princesses [...], qui est destinée au Prince Impérial Constantin Pawlowitsch ${ }^{26}$.

Le journal annonce des déplacements d'émigrés éminents vers Saint-Pétersbourg : « Le Duc de Polignac, qui avoit différé son départ pour la Russie, va incessamment se mettre en route avec sa Famille. A son arrivée à Pétersbourg, il prêtera serment entre les mains de l'Impératrice pour lui et un certain nombre de François émigrés, qui doivent aller habiter la portion du territoire que cette Souveraine leur a cédée ${ }^{27}$.

Le 31 décembre 1795 Baudus prévient ses lecteurs qu'il arrête son journal. Il explique sa décision par le manque " des moyens matériels ", " des correspondances mieux établies et des presses qui fussent exclusivement à notre disposition » et promet de renouveler la

\footnotetext{
${ }^{22}$ Journal d'Altona, 1795, 4 septembre, $\mathrm{n}^{\circ} 57$.

${ }^{23}$ Journal d'Altona, 1795, 5 septembre, $\mathrm{n}^{\circ} 58$.

${ }^{24}$ Journal d'Altona, 1795, 10 septembre, ${ }^{\circ} 62$.

${ }^{25}$ Journal d'Altona, 1795, 13 août, $\mathrm{n}^{\circ} 38$.

${ }^{26}$ Journal d'Altona, 1795, 18 novembre, $\mathrm{n}^{\circ}$ 121, 25 novembre, $\mathrm{n}^{\circ}$ 127. Julienne de Saxe-Cobourg-Saalfeld, grande-duchesse Anna Fedorovna (1781-1860).

${ }_{27}^{27}$ Journal d'Altona, 1795, 17 octobre, $\mathrm{n}^{\circ} 94$.
} 
publication au printemps ${ }^{28}$. Mais c'était probablement le dernier numéro du Journal d'Altona.

\section{L'Abeille}

La même année 1795, à Brunswick, Antoine Philippe Dubois des Cours, marquis de La Maisonfort, fonde une imprimerie où il lance la publication de L'Abeille ou le Journal littéraire et politique de Brunswic ${ }^{29}$. Dans cette entreprise, il profite du soutien de la cour ducale : il se souviendra avec reconnaissance du duc Karl Wilhelm Ferdinand qu'il appelle " mon digne protecteur, mon bienfaiteur, mon père ${ }^{30}$. La duchesse-mère PhilippineCharlotte, une sœur de Fréderic le Grand, encourage le projet éditorial du marquis. Ainsi elle adresse à Ernst Theodor Langer, responsable de la riche bibliothèque ducale, une lettre de recommandation où elle cite le marquis et sa femme parmi « des persones de merite qui ceront bien aise de faire votre conaissence a Volfenbuttel ».

Entre autre il y a ici un emigré françois nomé mr de Maisonfort qui compte s'etablir a Paques a Volfenbuttel. C'est un jeune home d'esprit et de talent qui songe a ecrire un journal nomee L'abeille pour suffire a sa triste fortune. Je vous le recomende peut etre pourrés vous l'aider a lui doner des materrieux pour parvenir a son ouvrage qui est assez jolie et pour lesquels il ce donne beaucoup de peine et vous aurai l'aventage de faire la conaissance de bien des gens d'esprit qui ceront charmes de voir non seulement votre personne mais aussi La bibliothèque ${ }^{31}$.

De La Maisonfort, ainsi que nombre de ses compatriotes réfugiés, a besoin de livres parce qu'il a dû laisser les siens en France, et il profite de la bibliothèque ducale, qui se trouve à Wolfenbüttel, pour ses loisirs et ses travaux littéraires ${ }^{32}$.

L'Abeille devient un hebdomadaire qui paraît durant neuf mois (janvier - septembre $\left.{ }_{1795}\right)^{33}$. En comparaison avec le Journal d'Altona, le périodique du marquis de La Maisonfort ne renseigne pas ses lecteurs uniquement sur les événements de la politique européenne, mais également sur la littérature (française et allemande).

On ne trouve pas beaucoup de contributions consacrées directement à la Russie. Il y a un seul texte développé sur ce sujet, c'est le compte-rendu du livre de Chantreau, Voyage philosophique, politique et littéraire fait en Russie ${ }^{34}$, un article d'une quinzaine de pages avec d'importants extraits du livre. Le compte-rendu commence par reprendre les anciens

\footnotetext{
${ }^{28}$ Journal d'Altona, 1795, 31 décembre, $\mathrm{n}^{\circ} 158$.

${ }^{29}$ Deutsche Presse, op. cit., Bd. 3 : Presse der Regionen Braunschweig / Wolfenbüttel, Hildesheim-Goslar / Britta Berg ; Peter Albrecht, Teil 1 (Braunschweig), Stuttgart-Bad Cannstatt, Frommann-Holzboog, 2003, $\mathrm{n}^{\circ} 146$, S. 347-351.

${ }^{30}$ Antoine-Philippe de La Maisonfort, marquis de, Mémoires d'un agent royaliste sous la Révolution, l'Empire et la Restauration 1763-1827, Paris, Mercure de France, 1998, p. 336.

${ }^{31}$ Herzog August Bibliothek (Wolfenbüttel). Handschriften BA II 113 fol. 54-54v. « Brunsvic ce 14 mars [1794 ou 1795$] »$.

${ }^{32}$ Mechthild Raabe, Leser und Lektüre im 18. Jahrhundert. Die Ausleibucher der Herzog August Bibliothek. Wolfenbüttel 1714-1799, Munich : K. G. Saur, 1989, Bd. 1, S. 258.

${ }^{33}$ Il existe une réédition de ce journal faite à Leipzig en 1797. L'Abeille ou mélanges littéraires et politiques. Rédigés par une société des gens des lettres. Ouvrage utile à tous ceux, qui en lisant aiment à joindre utile à agréable, seconde édition, Leipzig, chez A.L. Reinicke et J.C. Hinrichs, 1797, 3 t.

${ }^{34}$ Pierre Nicolas Chantreau, Voyage philosophique, politique et littéraire fait en Russie pendant les années 1788 et $1789 . .$. traduit du hollandais, avec une augmentation considérable, par le citoyen Chantreau,... Hambourg, Fauche, 1794, 2 vol.
} 
clichés du « mirage russe ${ }^{35}$. On mentionne « un peuple nouveau, sortant des ténèbres de la barbarie ». Un seul homme, Pierre $\mathrm{I}^{\mathrm{er}}$, a fait ses réformes "par miracle ». Pétersbourg est "une capitale aujourd'hui florissante, sortie tout à coup du sein des marais ». Mais le journaliste note chez Chantreau "un nouveau motif, qui tient aux circonstances ». Autrefois " on lisait le voyage de la Russie comme celui de la Chine [...] mais aujourd'hui que tant d'infortunés errent dans l'exil, [...] que tant de milliers d'hommes craignent à fuir leur patrie, on aime à se transporter quelques instants dans un pays lointain $»^{36}$. Outre ce compte rendu, on peut découvrir, dans les pages de l'Abeille, des nouvelles sur la politique russe en Pologne, sur les troupes commandées par Souvorov à Varsovie, sur les relations de la Russie avec la Grande Porte, sur « la flotte Russe [...], qui est destinée à la mer du Nord $»^{37}$.

On peut avoir une idée plus précise de l'image de la Russie dans les réflexions politiques du marquis de La Maisonfort en étudiant son ouvrage écrit à ce moment. En 1796, il publie chez Fauche son traité De l'État réel de la France à la fin de l'année 1795 et de la situation politique des puissances de l'Europe à la même époque (Hambourg: P. Fr. Fauche, 1796, t. 1-2), dont une dizaine de pages sont consacrées à la Russie. « Deux grands hommes » ont consolidé l'Empire : Pierre I ${ }^{\mathrm{er}}$ et Catherine II. «Le Czar Pierre a donné la Russie à l'Europe », " une femme qui fait régner comme Catherine, est un grandhomme ». "L'habitude de régner sur de vastes états a donné à l'impératrice de Russie celle des vastes idées ». « En se rapprochant de nos arts, comme de nous Elle [la Russie] arrivera aussi rapidement à sa civilisation qu'à sa splendeur ». Le marquis analyse avec lucidité la position de la Russie envers la France républicaine : « le cabinet de Pétersbourg est depuis longtemps celui, qui a jugé avec le plus de sagesse la révolution de la France ». Mais Catherine poursuit surtout les intérêts de son Empire : "Si la Russie a blâmé la révolution, il n'est pas bien clair pour cela qu'elle ait désiré franchement que tant de troubles fussent promptement apaisés ; en détestant des principes si dangereux en euxmêmes ; il est possible, qu'elle ait songé à en profiter, et que son but ait été depuis quatre ans d'acquérir dans les affaires de Pologne une influence d'autant plus grande sur ses deux alliés, que seule elle n'a point divisé ses forces et ne s'est occupée que d'un objet ${ }^{38}$.

Il est intéressant de noter qu'au moment où l'Abeille a déjà cessé de paraître, dans le milieu des royalistes ainsi qu'à la cour de Russie, on discute la question de la création d'un journal des émigrés à Brunswick.

Le marquis Henri Joseph de Lambert, agent de Catherine II, propose Jacques Mallet du Pan et Jean Joseph Mounier pour remplir cette tâche : « Mr. de Puysegur aura l'honneur de parler à Votre Altesse du projet d'un journal qu'elle daigneroit permettre d'établir à Brunsvic dans l'objet de retablir et de former l'opinion publique, Mallet du Pan, Mounier pouront y etre employé utilement ${ }^{39}$.

\footnotetext{
${ }^{35}$ Voir Albert Lortholary, Les «Philosophes » du XVIII siècle et la Russie : le mirage russe en France au XVIII siècle, Paris, 1951 ; Le Mirage russe au XVIII siècle, textes publiés par Sergueï Karp et Larry Wolff, FerneyVoltaire, Centre international d'étude du XVIII ${ }^{\mathrm{e}}$ siècle, 2001.

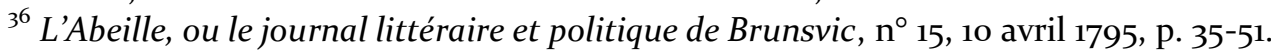

37 L'Abeille, ou le journal littéraire et politique de Brunsvic, $\mathrm{n}^{\circ} 3,16$ janvier 1795, p. 97 ; Supplément extraordinaire au Nro. 27 de L'Abeille ou le Journal littéraire et politique de Brunsvick, du Mercredi 7 Juillet 1795 .

${ }^{38}$ Antoine-Philippe de La Maisonfort, marquis de, De l'État réel de la France à la fin de l'année 1795 et de la situation politique des puissances de l'Europe à la même époque, Hambourg, P. F. Fauche, 1796, t. 2, p. 199209.

${ }^{39}$ Lettre à Karl-Wilhelm Ferdinand, le 26 décembre 1795. Niedersächsisches Landesarchiv Wolfenbüttel, 1 Alt 22, $\mathrm{n}^{\circ} 1945, \mathrm{f}^{\circ} 87 v$.
} 
Au début de 1796, lors de sa rencontre avec le représentant du roi en exil, le comte de Saint-Priest, Catherine II elle-même propose d'établir un journal périodique des émigrés dans la " résidence du duc de Brunswick ${ }^{40}$. Connaissait-elle l'existence de l'Abeille?

Mais le duc Karl-Wilhelm-Ferdinand s'oppose à cette idée. Il répond à Lambert : « Je pense comme Vous qu'un Journal pourroit être très utile. Mais Brunsvic n'est pas la ville qui convient, nous sommes trop dependans dans ces contrées de l'opinion du moment et je crois qu'une Ville libre de l'Empire conviendroit mieux à l'execution de ce projet. Comme Mr. le Cte de Puysegur vous parlera plus en detail sur les difficultés qui se présentent vous me permettrés bien de m'en rapporter à lui ${ }^{41}$. Effectivement, le nouveau périodique des émigrés paraîtra bientôt dans « une ville libre de l'Empire », à Hambourg.

\section{Le Spectateur du Nord}

A partir de 1797, le marquis de La Maisonfort s'associe à Fauche, avec qui il fonde la "Société littéraire et typographique de Brunswick». Grâce à cette coopération, Fauche reçoit le soutien de la cour ducale et des subventions importantes ${ }^{42}$. La rencontre avec le marquis provoque l'essor de la librairie de Fauche qui voit mise à sa disposition l'imprimerie de Brunswick. C'est à ce moment qu'il lance à Hambourg sa publication la plus connue, le Spectateur du Nord, journal politique, littéraire et moral. Ce périodique mensuel paraît pendant six ans, entre 1797 et $1802^{43}$. Il est conçu et dirigé par Amable de Baudus qui a déjà une expérience de collaboration avec Fauche au Journal d'Altona. À part ses travaux littéraires, Baudus s'occupe de l'entreprise de Fauche, qui est souvent absent pour ses voyages commerciaux.

Les archives privées de Baudus récemment découvertes permettent de démontrer l'importance du Spectateur pour les émigrés, d'identifier les auteurs des publications anonymes, d'étudier les détails de sa diffusion dans l'espace allemand, au Nord de l'Europe, et de comprendre quels étaient les contacts du journal avec la Russie ${ }^{44}$. Cette correspondance nous montre comment et par qui le rédacteur était renseigné.

Le Spectateur donne aux nombreuses personnes de l'émigration la possibilité de s'exprimer, et il permet aux Français en exil de retrouver leurs familles, leurs amis et compatriotes. En peu de temps, le nouveau journal rend son rédacteur célèbre. On s'adresse à Baudus comme à « Monsieur Le Spectateur du Nord $»^{45}$.

Baudus s'entoure des meilleures plumes parmi les émigrés (Antoine Rivarol, Charles de Villers, marquis de Mesmon, abbé Dellile, Joseph Alphonse Esménard, Louis de Fontanes,

\footnotetext{
${ }^{40}$ Ernest Daudet, Histoire de l'émigration pendant la Révolution française, Paris, 1905, t. 1, p. 360.

${ }^{41}$ Le 20 janvier 1796, Niedersächsisches Landesarchiv Wolfenbüttel, 1 Alt 22, $n^{\circ}{ }_{1945}, f^{\circ} 98 v$.

${ }^{42}$ Martina Graf, Buch-und Lesekultur in der Residenzstadt Braunschweig zur Zeit der Spätaufklärung unter Herzog Karl Wilhelm Ferdinand (1770-1806), Frankfurt am Main, Buchhändler-Vereinigung, 1994 (Archiv für Geschichte des Buchwesens, Bd. 42), S. 70-71.

${ }^{43}$ Deutsche Presse, op. cit., Bd. 1: Hamburg: kommentierte Bibliographie der Zeitungen, Zeitschriften, Intelligenzblätter, Kalender und Almanache sowie biographische Hinweise zu Herausgebern, Verlegern und Druckern periodischer Schriften, Holger Böning ; Emmy Moepps, Teil 3 : 1796-1815, Stuttgart-Bad Cannstatt, Frommann-Holzboog, 1996, $\mathrm{n}^{\circ} 760$, S. 1600-1608.

${ }^{44}$ François Richard, Amable de Baudus: 1761-1822, Saint-Maure, F. Richard, 2010, t. 1-4. Afin d'éviter les erreurs présentes dans cette publication importante, les documents des archives privées de Baudus sont cités ici d'après les originaux. Je tiens à remercier Madame Florence de Baudus de m’avoir donné accès à ces archives.

${ }^{45}$ Voir : Florence de Baudus, Amable de Baudus, des services secrets de Talleyrand à la direction de la Censure sous Louis XVIII, Paris, Editions SPM, 2012, p. 62.
} 
etc.), parmi les écrivains allemands (Archenholtz, etc.), suédois (Gjoerwell), russe (Karamzine). Il se réserve l'exclusivité de la partie politique.

Le Spectateur présente des nouvelles de la littérature et des librairies française et allemande, parfois de la littérature anglaise, suédoise et russe (traductions, comptes rendus, extraits). Baudus et ses collègues veulent renseigner les Français sur l'Allemagne et les Allemands sur la France et désirent " rapprocher des peuples », " les faire connaître les uns aux autres ». On peut y trouver des informations sur la politique européenne, sur les affaires diplomatiques et militaires. Ce journal d'un ton modéré et d'un caractère cosmopolite est largement diffusé notamment au nord de l'Europe, y compris en Russie. $\mathrm{Au}$ début, il est admis en France, mais il est bientôt interdit par le Directoire ${ }^{46}$. Pour éviter des poursuites de la part des pouvoirs républicains, son éditeur, P. F. Fauche, " homme prudent se désolidarise de la rédaction ${ }^{47}$ et remplace, sur la page de titre, le nom de la ville de Hambourg par celui du Holstein et ensuite par celui de la Basse Saxe, mais les Mémoires du marquis de La Maisonfort, ainsi que les archives privées de Baudus nous apprennent que le Spectateur du Nord était imprimé d'abord à Hambourg et ensuite à Brunswick ${ }^{48}$.

\section{Journal littéraire et bibliographique}

Chaque numéro du Spectateur contient des annonces de nouveaux livres français. En 1799, une nouvelle publication mensuelle de Fauche paraît à Hambourg sous le titre Journal littéraire et bibliographique ${ }^{49}$. Ce périodique n'est rien d'autre qu'un supplément au Spectateur ; il annonce des nouveautés de l'édition française à travers toute l'Europe. Le résumé de chaque ouvrage traité, très bref au début de l'existence du Journal, devient bien plus développé par la suite. Les articles, tirés des périodiques publiés en France, sont anonymes, les textes écrits par les collaborateurs eux-mêmes, sont signés de leurs initiales. La production de la maison Fauche et $C^{\text {ie }}$ et l'assortiment de ses librairies est bien entendu largement représentée. Parmi les ouvrages recensés - quelques centaines dans les quatre années de l'existence de ce journal - la place des Russica n'est pas importante, une douzaine de titres seulement. Les livres signalés sont différents par leur qualité et par leur orientation politique. On y trouve le pamphlet de Charles Laveaux, Histoire de Pierre III [...], suivie de l'histoire secrète des amours et des principaux portraits des amants de Catherine $I I^{50}$, avec cette caractéristique : « c'est encore une fois un libelle sur Catherine» rédigé par un «compilateur républicain $»^{51}$. Par contre, on apprécie la nouvelle édition de l'Histoire de Russie par Pierre-Charles Levesque (réimprimée par Fauche $)^{52}$. Parmi les traductions des ouvrages russes, le journal cite les publications de L.

\footnotetext{
${ }^{46}$ Paul Hazard, « Le Spectateur du Nord », Revue d'histoire littéraire de la France, 1906, p. 35.

${ }^{47}$ Fernand Baldensperger, Le mouvement des idées dans l'émigration française (1785-1815), t. 1, p. 164-165.

${ }^{48}$ Antoine-Philippe de La Maisonfort, marquis de, Mémoires d'un agent royaliste sous la Révolution, l'Empire et la Restauration 1763-1827, Paris, Mercure de France, 1998, p. 223, 239-242.

${ }^{49}$ Deutsche Presse, op. cit., Bd. 1 : Hamburg, op. cit., Bd. 1, Teil 3, n' 787, S. 1633-1635.

$5^{\circ} \mathrm{J}$. Ch. Laveaux, Histoire de Pierre III, empereur de Russie : imprimée sur un manuscrit trouvé dans les papiers de Montmorin, ancien ministre des affaires étrangères, et composé par un agent secret de Louis XV, à la cour de Pétersbourg; avec des éclaircissemens et des additions importantes ; suivie de l'histoire secrète des amours et des principaux amans de Catherine II, Paris, Briffe, VII (1799), 3 t.

${ }^{51}$ Journal littéraire et bibliographique, 1799, janvier, p. 31-32.

${ }^{52} \mathrm{P}$. Ch. Levesque, Histoire de Russie. Nouvelle édition, corrigée et augmentée par l'auteur, et conduite jusqu'a la mort de l'impératrice Catherine II, Hambourg et Brunswick, chez Pierre-François Fauche et Compagnie, 180o, 8 t. ; Journal littéraire et bibliographique, 180o, mars, p. 126 ; 180o, avril, p. 121-126.
} 
Pappadopoulo Choix des meilleurs morceaux de la littérature russe (Paris, 180o) et Théâtre tragique d'Alexandre Soumarokov (Paris, 1801) ${ }^{53}$.

\section{La Russie dans le Spectateur du Nord}

Dans la partie littéraire du Spectateur, également, on ne trouve qu'un petit nombre de textes «russes». Les quelques 70 fascicules parus pendant six années ne comportent qu'une vingtaine de publications consacrées directement à la Russie, y compris des comptes rendus.

Le premier numéro daté du mois de janvier 1797, c'est-à-dire deux mois après la mort de Catherine II, publie une recension favorable d'une brochure anonyme l'Ombre de Catherine II aux Champs Elysées, portant la fausse adresse typographique «Au Kamtchatka ». Ce pamphlet, rédigé probablement par l'un des émigrés, discutait des problèmes de la coalition contrerévolutionnaire ${ }^{54}$.

Dans le deuxième numéro du mois de février 1797, on insère le texte intégral de Julie, nouvelle sentimentale de Nicolaï Karamzine. En présentant l'écrivain comme l'un de ses correspondants, Baudus suppose que cet ouvrage "suffira pour faire voir que dans un pays qu'en France on ne se déshabitue pas encore de regarder comme un peu barbare, ils se trouvent des écrivains qui peuvent rivaliser avec les Marmontel et avec les Florian ${ }^{55}$. La version russe de Julie a été publiée à Moscou en 1796, la publication du Spectateur en est la première traduction. Le traducteur, un certain Monsieur de Bouillers, suit fidèlement le texte original ${ }^{56}$.

Dans le même cahier du mois de février de 1797, on trouve une « Lettre au Spectateur sur Pierre III », signée par un « Voyageur ». Youri Lotman a supposé que ce « Voyageur » n'était autre que Karamzine ${ }^{57}$, néanmoins cette hypothèse reste toujours à confirmer. La rédaction explique que cette lettre « vient de quelqu'un qui partage vivement le desir qu'a manifesté Paul I. de réhabiliter dans l'opinion la mémoire de son malheureux père ».

\footnotetext{
${ }^{53}$ Journal littéraire et bibliographique, 1801, p. $64 ; 1802$, p. 29.

${ }^{54}$ Le Spectateur du Nord, 1797, janvier, p. 155; L'Ombre de Catherine II aux Champs Elysées, Au Kamtchatka, 1797. Voir Владимир А. Сомов, «Французская «Россика» эпохи Просвещения и русский читатель », Французская книга в России в XVIII веке: Очерки истории [Vladimir A. Somov, «'Russica' français du siècle des Lumières et son lectorat russe », Le livre français en Russie au XVIII siècle], Leningrad, 1986, p. 198 ; Василий А. Бильбасов, История Екатерины Второй [Vassili A. Bilbassov, Histoire de Catherine II], [Berlin], 1900, t. 12, part. 2, p. 23-25, 34-35; on peut supposer que ce livre fut imprimé par Pierre François Fauche.

${ }^{55}$ Le Spectateur du Nord, 1797 , février, p. 183.

${ }^{56}$ On trouve à la Bibliothèque nationale de Russie une publication à part de la même traduction avec l'adresse typographique «A Moscou, chez François Courtener, Libraire, 1797». Le bibliographe russe Sergueï Poltoratski, qui a collationné ce livre avec le texte du Spectateur, a supposé que cette version moscovite était également sortie des presses de Fauche pour être diffusée avec une fausse adresse typographique. Voir les notes de S. Poltoratski sur un exemplaire de ce livre conservé à la Bibliothèque nationale de Russie. (Cote RNB: 13.16.8.81). C'est bien probable parce que François Courtener était un commissionnaire du libraire hambourgeois.

57 Юрий М. Лотман, «Черты реальной политики в позиции Карамзина 1790-х гг. (к генезису исторической концепции Карамзина) », Проблемы историзма в русской литературе: Конец XVIII начало XIX в. [Juri M. Lotman, «Les traits de la politique réelle dans la position de Karamzine dans les années 1790 ", Problèmes de l'historicisme dans la littérature russe : Fin du XVIII - début du XIX ${ }^{e}$ siècles], Leningrad, 1981, (XVIII век. Сборник 13 [XVIII siècle, fasc. 13]), р. 102-131 ; Николай М. Карамзин, Письма русского путешественника, издание подготовили Ю.М. Лотман, Н.А. Марченко, Б.А. Успенский [Nikolaï Karamzine, Lettres d'un voyageur russe, éd. de Ju.M. Lotman, N.A. Martchenko, B.A. Ouspenski], Léningrad, 1984, p. 678-679.
} 
Le « Voyageur » écrit :

L'Europe abusée [...] n'a jugé ce Prince que sur les rapports de ses mortels ennemis, où de leurs lâches partisans [...] Catherine II régna, et sa gloire remplit le monde. Des Philosophes en furent les héraults ; l'ami de vérité ne doit pas les contredire ; mais ne lui est-il pas permis de compter le nombre d'hommes, de femmes et d'enfants que, durant plus de trente années, cette gloire coûte à la Pologne, à la Suède, à la Turquie, à la Perse, et surtout à la Russie ? $5^{58}$

Ce regard critique rencontre un écho favorable de la part de la rédaction : le numéro suivant du Spectateur contient un compte rendu d'un célèbre ouvrage de Claude Carloman Rulhière sur la « révolution » de l'année $1762^{59}$. Ce livre qui racontait en détail les circonstances de l'avènement de Catherine au trône, démontrait son rôle essentiel dans la conspiration contre son mari, l'empereur Pierre III. Les pouvoirs russes voulaient par tous les moyens empêcher la publication de l'ouvrage qui ne pourra paraître qu'en 1797, après la mort de l'impératrice.

Le Spectateur a bien apprécié le livre : «C'est le récit d'un homme qui a assisté à la révolution de 1762, qui sçavoit bien voir, qui étoit à portée de tout voir, et qui raconte tout ce qu'il a vu, tout ce qu'il a sçu ». On signale avec satisfaction : "L'ouvrage étoit à peine publié à Paris, lorsque nous avons reçu de la Russie la lettre sur Pierre III, qui se trouve dans notre dernier numéro. Les faits qui y sont rapportés sont confirmés par l'ouvrage de Mr. de Rulhières » ${ }^{60}$.

Les jugements critiques sur Catherine inquiètent les émigrés. Ainsi, l'abbé Joseph François Marie, un collaborateur énergique de Baudus, lui reproche ce genre de publications : "Ce qui m'en plaît le plus, Monsieur, c'est que vous y êtes très impartial ; au lieu que, dans le $n^{\circ}{ }_{2}$ surtout, vous aviez pris tellement couleur contre l'Angleterre et même contre la feue impératrice de Russie que vous aviez l'air d'être en contradiction avec vos principes connus » (3 avril 1797).

Le même abbé Marie transmet les rumeurs sur un autre ouvrage célèbre consacré à l'impératrice : «On dit que c'est Genêt qui est l'auteur de la vie de Catherine II. Je connais le pèlerin : c'est au moins un ingrat et un énergumène. Pourquoi M. Fauche imprime-t-il de tels ouvrages ? Quaerenda pecunia primum est ${ }^{61}$. N'est-ce pas ? " (21 décembre 1797). On sait actuellement que ce n'est pas Edmond Charles Genêt, chargé d'affaires français à Saint-Pétersbourg au début de la Révolution, mais Jean Henri Castéra, homme de lettres, agent diplomatique du gouvernement républicain, qui est l'auteur de la Vie de Catherine II. Ce livre a été diffusé largement en Europe et même en Russie où, proscrit par la censure, il a été fort apprécié des lecteurs ${ }^{62}$. L'information de Marie permet de supposer que l'une des éditions de cet ouvrage célèbre a été imprimée chez Fauche.

Catherine II ne reçoit pas beaucoup d'éloges dans le Spectateur. Il y a bien une tentative de redorer son image, mais elle échoue. En effet, Petr Doubrovski, célèbre bibliophile, à l'époque secrétaire de la Légation russe à Hambourg, organise, en 1797, un concours poétique pour rendre hommage à l'impératrice. Amable de Baudus fait partie des personnes invitées par Doubrovski pour juger les ouvrages envoyés. Après la répartition des prix, Baudus veut publier les meilleures odes de cette compétition dans le

\footnotetext{
${ }^{58}$ Le Spectateur du Nord, $1797, \mathrm{n}^{\circ}$ 2, p. $283^{-288 .}$

${ }^{59}$ Claude Carloman de Rulhière, Histoire, ou anecdotes sur la révolution de Russie en 1762, Paris, 1797.

${ }^{60}$ Le Spectateur du Nord, $1797, n^{\circ} 3$, p. 435-436.

${ }^{61}$ Epistularum Q. Horatii Flacci Liber Primus.

${ }^{62}$ Vladimir A. Somov, "Le livre de Castéra d'Artigues sur Catherine II et sa fortune ", Catherine II $\mathcal{E}$ L'Europe, sous la dir. d'Anita Davidenkoff, Paris, 1997, p. 211-224.
} 
Spectateur, mais Doubrovski l'en empêche, craignant le mécontentement de SaintPétersbourg : Paul I ${ }^{\mathrm{er}}$, dont les relations avec sa mère n'ont jamais été bonnes, ne respecte pas autant sa mémoire.

Le rédacteur présente ses explications à Doubrovski (28 mai 1797).

Monsieur,

Ce n'est pas à moi, mais bien à $\mathrm{M}^{\mathrm{r}}$. de Rivarol que les odes dont vous me parlez ont été confiées et c'est lui qui a rédigé le procès-verbal. J'avais compté, il est vrai, les faire connaitre dans le premier № de mon journal, mais par égard pour la société russe qui a proposé le prix, je n'en parlerais que lorsqu'elle n'y trouvera plus d'inconvénient. Vous pourrez même reprendre les odes, quand vous le trouverez bon.

J'ai l'honneur d'être avec une considération distinguée,

Monsieur,

Votre très humble et très obéissant serviteur

Baudus. ${ }^{63}$

Finalement, le recueil contenant les meilleurs poèmes de la compétition est sorti à Hambourg des presses de Fauche en quarante exemplaires seulement, comme en témoignent les factures présentées par ce libraire à Doubrovski ${ }^{64}$.

La même année 1797, au mois d'octobre, le journal présente une publication anonyme "Lettre au Spectateur sur la littérature russe ». Cette "Lettre » a une grande importance pour l'histoire de la littérature en Russie, pour l'histoire des contacts littéraires, et elle n'a cessé d'attirer l'attention des chercheurs. On sait actuellement qu'elle a été rédigée par Karamzine ${ }^{65}$.

Sa contribution consiste en deux parties. La première contient un bref aperçu de l'histoire de la littérature russe, la seconde représente l'abrégé des « Lettres du voyageur russe », ouvrage de Karamzine lui-même, dont il cite de larges extraits en traduction française.

Dès le début, Karamzine constate : "Le génie est de tous les climats, et en Russie même il y a des gens de talens, qui sont assez modestes pour ne pas disputer la palme aux littérateurs français, allemands, etc. mais qui, en lisant leurs immortels ouvrages, peuvent se dire, et nous aussi, nous sommes peintres !» ${ }^{66}$ Il dit que les Russes cultivaient la poésie «bien avant le temps de Pierre le Grand» et, pour soutenir son affirmation, il cite « Le

\footnotetext{
${ }^{63}$ RNB Ms Autographe 147, fol. 274-275 v.

64 Тамара П. Воронова, «Литературный конкурс 1797 г. в Гамбурге, посвященный Екатерине II (по материалам архива П. П. Дубровского)», Археографический ежкегодник за 2004 год [Tamara P. Voronova, «La compétition littéraire de Hambourg consacrée à la mémoire de Catherine II (d'après les archives de P. P. Doubrovski », Annuaire archéographique pour l'année 2004], Moscou, 2005, p. 382-387; Vladimir A. Somov, «Piotr Doubrovski et la communauté d'émigrés français de Saint-Pétersbourg (17971812) », La France et les Français en Russie : Nouvelles sources et approches (1815-1917), études réunies par Annie Charon, Bruno Delmas et Armelle Le Goff, Paris, 2011 (Études et rencontres de l'École des chartes, 34), p. 287-289. L'abbé Marie a publié son Ode dans une édition séparée : Odes sur la mort de Catherine II, impératrice de toutes les Russies, par M. l'abbé Marie, Hambourg : P. F. Fauche, 1797.

${ }^{65}$ Письма Н.M. Карамзина к И.И. Дмитриеву [Lettres de N.M. Karamzine à I.I. Dmitriev], publ. par Ia.K. Grot et P.P. Pékarski, Saint-Pétersbourg, 1866, p. 44-186 ; Николай М. Карамзин, «Несколько слов о русской литературе. Письмо в «Зритель о русской литературе », Николай М. Карамзин, Избранные сочинения в двух томах [Nicolaï M. Karamzine, "Quelques mots sur la littérature russe: Lettre au Spectateur sur la littérature russe », Nicolaï M. Karamzine, Euvres choisies], introduction de P.N. Berkov et G.P. Makogonenko, Leningrad, 1964, t. 2, p. 145-155, 532-533; Николай М. Карамзин, Письма русского путешественника [Nikolaï Karamzine, Lettres d'un voyageur russe], op. cit., p. 449-463.

${ }^{66}$ Le Spectateur du Nord, 1797, octobre, p. 53-54.
} 
chant des guerriers d'Igor »(Le Dit de l'Ost d'Igor ${ }^{67}$. Cette mention était la première annonce en Occident de l'existence de ce grand monument de la littérature russe médiévale ${ }^{68}$.

Karamzine écrit ensuite :

Quand Pierre le Grand déchira le rideau qui cachoit à nos yeux les nations civilisées de l'Europe et les progrès de leurs arts, le Russe, humilié par le sentiment de son inferiorité, mais se sentant capable d'instruction, voulut imiter les étrangers en tout, dans la façon de vivre comme dans le costume, dans les moeurs comme dans les arts ; il modela sa langue sur celle des Allemands, des Français, et notre poësie, notre littérature devinrent l'écho et la copie des leurs.

Depuis ce tems, nous nous sommes essayés, avec assez de succès, dans presque tous les genres de littérature ${ }^{69}$.

Mais en proclamant le progrès de la littérature russe, l'écrivain démontre aussi les défauts de sa Patrie "dans un pays où le rang fait tout, la renommée a peu de charmes $»^{70}$.

Karamzine ne mentionne aucun nom d'écrivain, même pas le sien, bien qu'une grande partie de cet article soit consacrée à ses propres écrits. On a supposé avec raison que sa Lettre sur la littérature garde des traces des versions initiales des Lettres du voyageur russe $^{71}$, par contre il faut noter qu'elle est rédigée " pour les étrangers » et écrite «à la française », d'après la déclaration de l'écrivain-même faite dans sa correspondance avec Ivan Dmitriev ${ }^{72}$.

Les chercheurs russes et occidentaux se sont longtemps intéressés aux contacts entre Karamzine et le Spectateur du Nord. Récemment, grâce à l'amabilité de Madame Florence de Baudus, on a obtenu de nouveaux témoignages concernant cette histoire. Il s'agit d'une lettre de Karamzine à Baudus. C'est une réponse à la proposition de devenir un correspondant du journal. L'écrivain donne son accord pour la collaboration :

Moscou, le 11/22 Janvier, 1797.

Monsieur,

J'ai eu l'honneur de recevoir vôtre obligeante lettre. En supposant notre litterature digne de votre attention et de celle de vos lecteurs, vous engagez tous les auteurs russes à redoubler d'efforts pour meriter cette bonne opinion ; et c'est avec bien du plaisir que je me charge de vous rendre compte de leurs succès. L'honneur d'être votre correspondant me suffit, Monsieur, et je ne pretends à aucun bénéfice. Les gens de lettres de tous les pays ne forment qu'une même republique et doivent se regarder comme des frères : cette idée charme mon coeur, et me console souvent dans mon isolement litteraire, dans un pays, où la Nature sourit peu à l'imagination d'un homme sensible. Le plan de votre journal est très beau, très vaste, et bien adapté aux circonstances du tems. Ecrivez, Monsieur, ecrivez pour le bien des hommes: vous êtes heureux de pouvoir dire tout ce qui se presente à votre esprit comme verité, comme une idée lumineuse.

${ }^{67}$ Le Spectateur du Nord, 1797, octobre, p. 55.

68 Лев А. Дмитриев, « Карамзин Николай Михайлович », Энциклопедия «Слова о полку Игореве» [Lev A. Dmitriev, "Karamzine Nikolaï Mikhaïlovitch », "Le Dit de l'Ost d'Igor», Encyclopédie], t. 3, SaintPétersbourg, 1995, p. 14-18.

${ }^{69}$ Le Spectateur du Nord, 1797, octobre, p. 56.

${ }^{70}$ Le Spectateur du Nord, 1797, octobre, p. 57.

${ }^{71}$ Николай М. Карамзин, «Несколько слов о русской литературе. Письмо в «Зритель о русской литературе », op. cit., t. 2, p. 145-155, 532-533; Николай М. Карамзин, Письма русского путешественника, ор. cit., p. 449-463.

${ }^{72}$ Письма Н.М. Карамзина к И.И. Дмитриеву, ор. cit., Saint-Pétersbourg, 1866, p. 92. 
Vous pouvez vous abandonner, sans crainte, aux élans d'un noble enthousiasme, et l'Europe vous lira, vous applaudira.

$\mathrm{M}^{\mathrm{rs}}$ Riss et Saucet vous feront parvenir, de tems en tems, quelques extraits, que je leur remettrai pour vous, et vous aurez la bonté d'en corriger le style; mais je vous prie, monsieur, de ne me point nommer, si vous les faites paroitre dans votre journal ; j’ai mes raisons pour cela.

Oserai-je vous charger d'une commission, intéressante pour mon coeur? Etant à Hambourg, vous voyez sans doute le grand Klopstok : voudriez-vous bien lui dire qu'au milieu des glaces du Nord il existe une ame, sensible aux beautés sublimes de ses immortelles productions, et qu'elle s'échauffe souvent au feu de son genie? Nommez moi ensuite. Les grands poëtes ne peuvent pas être indifferents aux hommages purs de leurs sinceres admirateurs. - Agréez l'assurance de la haute consideration, avec laquelle j’ai l'honneur d'être.

Monsieur,

Votre très - humble et très - obeissant serviteur,

Karamsine.

Cette lettre est adressée à « Monsieur Fauche, libraire à Hambourg pour remettre à Monsieur Baudus ». Les Riss et Saucet, cités par Karamzine, sont des partenaires moscovites de Fauche qui s'occupent de la vente du livre français. Avec leur réseau bien constitué, les libraires sont des médiateurs solides entre les membres de la République des lettres dont Karamzine fait l'éloge.

Sa lettre à Baudus montre qu'il veut écrire ses contributions en français lui-même tout en gardant son incognito. Baudus respecte sa volonté. Il annonce uniquement en publiant la Julie, que Karamzine a accepté d'être son correspondant. Nous pouvons supposer que c'est Karamzine lui-même qui envoie la traduction française de sa nouvelle. Il n'est pas exclu qu'il l'ait traduite lui-même ou bien qu'il ait participé au travail de ce Monsieur de Bouillers, dont nous ne savons rien.

La correspondance de Karamzine avec Ivan Dmitriev démontre que ses relations avec le Spectateur continuent après la publication de la Lettre sur la littérature russe, et qu'il a l'intention d'envoyer à Baudus d'autres de ses écrits. Mais rien n'est plus paru dans le Spectateur, probablement parce qu'il n'a rien envoyé. Le moment n'était pas favorable pour les contacts internationaux des écrivains, la censure russe devenait de plus en plus sévère.

Il faut constater, qu'en répondant à la demande de Baudus, Karamzine a soutenu le programme éditorial de son confrère français, il a présenté aux lecteurs européens l'histoire et l'état contemporain de la littérature russe. Karamzine se rend aussi compte que cette publication "franco-allemande » est accessible à ses compatriotes malgré les interdictions de la censure. D’autre part, sa participation dans le célèbre journal contribue à la renommée internationale de l'écrivain. Notons que Karamzine n'est pas le seul correspondant russe du Spectateur : par exemple, au mois de novembre 1802, le journal publie une poésie du comte Fiodor Golovkin ${ }^{73}$.

Hormis cette petite quantité de textes soi-disant « russes », on trouve presque dans chaque cahier du Spectateur diverses mentions de la Russie et de sa politique extérieure. Elles apparaissent dans les rubriques "Correspondances diverses », "Coup d'œil sur les événements les plus récents » et parmi les nouvelles venant de Paris, de Londres, de La Haye, de Copenhague, de Berlin, de Stockholm et notamment de Basse-Saxe, où se trouve

\footnotetext{
${ }^{73}$ Le Spectateur du Nord, 1802, novembre, p. 183-185.
} 
la rédaction. Ces nouvelles sont le plus souvent brèves, mais parfois ce sont de longs textes de plusieurs pages présentant une analyse détaillée des événements. Baudus luimême s'occupe de la section politique du journal.

Parmi les personnalités russes, le Spectateur présente tout d'abord la figure de Paul I ${ }^{\mathrm{er}}$, dont le règne (1796-1801) coïncide presque avec les dates d'existence du journal (17971802). Les émigrés devaient apprécier que Paul ait décidé d'intervenir dans la lutte contrerévolutionnaire et qu'il soit un membre actif de la deuxième coalition : désormais l'Empire se trouvait directement en guerre avec la République et l'invasion russe menaça la France en $1799^{74}$. Cette année-là, le Spectateur présente un éloge poétique de Paul I ${ }^{\mathrm{er}}$, signé par Louis Auguste Bertin d'Antilly. « Le poëte finit par appeller au nom des Français la puissance de Paul $\mathrm{I}^{\mathrm{er}}$ sur leurs oppresseurs », résume le journal en citant son poème : «Paul, tu seras pour nous la suprème justice », etc. ${ }^{75}$

L'Empereur n'est pas critiqué non plus à l'heure du rapprochement franco-russe, quand il change ses intentions et se retire des armées de la coalition. Au mois de mars 180o, on écrit : «Paul I, en s'occupant avec zèle de la cause générale, ne perd pas de vue les intérêts de son pays $»^{76}$. La politique de Paul évolue, mais le Spectateur lui reste toujours favorable, ce qui permet d'interroger les liens invisibles existant entre ce périodique et la Russie. Après la mort du tsar, on publie, au mois d'avril 1801, un article développé sur les conséquences de cet événement pour "les affaires générales de l'Europe ${ }^{77}$. Les circonstances de cette mort ne sont pas rapportées, alors que le Spectateur est bien renseigné. C'est Amable de Baudus, à cette époque correspondant secret de Talleyrand, qui informe le ministre de l'assassinat de l'empereur ${ }^{78}$. En juin 1801, le Spectateur glorifie déjà "la sagesse d'Alexandre». On signale que «le génie de Catherine, qui anime aujourd'hui le cabinet de Pétersbourg, semble chercher comme autrefois à tenir la balance entre ces deux nations ", la France et l'Angleterre ${ }^{79}$. Le Spectateur n'oublie pas Pierre le Grand qui a " déchiré le rideau » entre la Russie et « les nations civilisées de l'Europe », mais c'est l'actualité politique qui intéresse les journalistes. Ainsi, quand le Spectateur publie en 1802 des extraits des journaux français consacrés au poème de Thomas, la Petréide ${ }^{80}$, et une Anecdote russe sur Catherine $\mathrm{I}^{\mathrm{re}}$, la femme du Tsar, emprunté à Oliver Goldsmith ${ }^{81}$, ces publications témoignent en premier lieu de l'intérêt pour ces écrivains.

Outre les monarques russes, des diplomates et des hommes d'Etat apparaissent dans les pages du Spectateur: le sénateur, puis chancelier Alexandre Vorontsov et son frère Semen Vorontsov, ministre à Londres, Nikita Petrovitch Panine, ministre à Berlin, Stepan Kolytchev, ambassadeur à Paris, le général Sprengporten, représentant de Paul I ${ }^{\mathrm{er}}$ pour les négociations avec Napoléon, etc. Mais c'est la figure d'Alexandre Souvorov qui attire le plus l'intérêt des Français. A cette époque, le «terrible et horrible » Souvorov menant la guerre en Italie contre les armées du Directoire devient la cible de la presse parisienne qui noircit son portrait ${ }^{82}$. Au contraire, les émigrés mettent leurs espérances en Souvorov qui

\footnotetext{
74 Charles Corbet, A l'ère des nationalismes : L'opinion française face à l'inconnue russe (1799-1894), Paris, Didier, 1967, p. 18.

${ }^{75}$ Le Spectateur du Nord, 1799, septembre, p. 381-394.

${ }^{76}$ "Sur la situation de l'Europe. Par un Cosmopolite », Le Spectateur du Nord, 1801, mars, p. 471.

77 «Coup d'oeil sur la situation de l'Europe. De la Basse Saxe, 30 avril 1801 », Le Spectateur du Nord, 1801, avril, p. 131-147.

${ }^{78}$ Florence de Baudus, Amable de Baudus..., p. 150-151.

${ }^{79}$ "Coup d'oeil sur la situation de l'Europe », Le Spectateur du Nord, 180o, juin, p. 448, 450.

${ }^{80}$ Le Spectateur du Nord, 1802, juin, p. 328-339.

${ }^{81}$ « Anecdote russe », Le Spectateur du Nord, 1802, septembre, p. 368-372.

${ }^{82}$ Charles Corbet, A l'ère des nationalismes, op. cit., p. 38-39.
} 
remporte des victoires sur les troupes républicaines. Toute l'année 1799, son nom ne disparaît pas des pages du Spectateur. Au mois de mars, on peut lire : " l'Europe étoit impatiente de voir ce héros, digne de plus beau temps de l'antiquité, à la tête de cent mille russes en Italie ${ }^{83}$. Au mois de juillet : « Souvoroff paroit destiné à jouer en Europe un trop grand rôle pour qu'on ne soit pas curieux d'avoir sur lui quelques détails. [...] Il est noble, généreux, humain et bon, joignant à la politesse des mœurs un esprit naturel et très cultivé. Il sait plusieurs langues étrangères, il parle bien et aime beaucoup le français. [...] Cet homme extraordinaire réunit les qualités raffinées de l'Européen à l'exagération asiatique, et les manières du courtisan à celles du Tartare ${ }^{84}$. Au mois de septembre, on publie un extrait du livre d'un voyageur et poète allemand Johann Gottfried Seume, à l'époque un officier au service russe, qui a «personnellement connu» Souvorov à Varsovie. Seume témoigne: «Tout son art consiste dans la térrible énergie qu'il sait donner à l'ame de ses soldats, qui sous lui se croient invincibles. Il est l'idole des troupes russes et le sera bientôt des troupes autrichiennes. C'est l'homme le plus fait pour gagner les cœurs de toute une armée ». «Il vint et vainquit ${ }^{85}$.

Pour les émigrés il est difficile à ce moment, même presque impossible, de faire abstraction de la Russie. La destinée de Germain Hyacinthe de Romance, marquis de Mesmon, un des anciens collègues de Baudus, le confirme.

\section{Le Réveil}

Le marquis de Mesmon fournit au Spectateur en 1797 plusieurs textes consacrés à la philosophie, à la morale, et aux belles-lettres. Outre cela, Baudus, en rendant compte de ses attachements à l'Angleterre, lui demande des notices sur les productions les plus récentes de la littérature anglaise. Mais le marquis, qui était souvent mécontent de la qualité de l'impression, faite à Brunswick, et de l'attitude des éditeurs (Fauche et de La Maisonfort), a finalement refusé de participer au Spectateur (Lettres à Baudus du 1 septembre, 1, 15, 17, 18 décembre 1797).

Il lance son propre journal : Le Réveil : ouvrage périodique, moral et littéraire dans le Genre anglais ${ }^{86}$. C'est un mensuel sortant à Hambourg, chez le libraire François Guerrier, qui existe pendant deux années, 1798 et 1799. Le Réveil est consacré en premier lieu à la littérature, et manifeste le goût du rédacteur pour la culture anglaise, comme en témoigne le titre même du journal.

Mesmon propose à ses abonnés « un cahier de quatre feuilles in- $8^{\circ}$ ou 64 pages par mois. Chaque livraison paraîtra le premier jour du mois, et la totalité pour l'année sera de 48 feuilles, distribuées en 2 vol. in- $8^{\circ}$ de 24 feuilles chacun ou près de 400 pages ${ }^{87}$. On peut constater l'absence presque totale d'informations sur la Russie, fait qui s'explique par l'absence de sujets politiques.

\section{Le Censeur}

\footnotetext{
${ }^{83}$ «Fragment de l'histoire des dernieres années du dix-huitième siècle », Le Spectateur du Nord, 1799, mars, p. 463.

${ }^{84}$ Le Spectateur du Nord, 1799, juillet, p. 144-146.

${ }^{85}$ Le Spectateur du Nord, 1799, septembre, p. 309-321.

${ }^{86}$ Le Réveil : ouvrage périodique, moral et littéraire dans le Genre anglais, t. 1 - 3 (1798-1799), Hambourg, chez François Guerrier, libraire, au Jacobi Kirhhof, 1798-1799, 3 vol. ; Deutsche Presse, Bd. 1 : Hamburg, op. cit., $\mathrm{n}^{\circ} 772$, S. $1623-1624$.

${ }^{87}$ Le Réveil, 1798, t. 1, p. 4.
} 
Après la fermeture du Réveil, le marquis de Mesmon s'est lancé dans une nouvelle entreprise éditoriale. En compagnie d'un autre émigré, Louis Augustin Bertin d'Antilly il publie : Le Censeur, journal politique et littéraire, En Basse Saxe [Hambourg], 1800 ${ }^{88}$. Cet hebdomadaire est assez mince, il est composé de seize pages in- $8^{\circ}$, et paraît tous les samedis. Les libraires Fauche et Guerrier s'occupent de la diffusion du Censeur. A la différence du Réveil, ce journal a une section «Politique». Il est orienté contre la France républicaine et s'oppose aux actions de Napoléon. Parmi les actualités européennes, on trouve ici les nouvelles des déplacements des armées russes, de l'activité de Souvorov, de la destinée de l'armée de Condé sur le territoire russe, etc. ${ }^{89}$

Même dans la section "Littérature » on insère des textes consacrés à la Russie, par exemple Quatrain improvisé à la vue d'un portrait de Paul $I^{e r}$ signé par le Chevalier De Gaufretaut, une poésie qui glorifie l'empereur :

\section{Effroi des sectateurs d'une morale impie, \\ Du trône et de l'autel il protège les droits ; \\ Le crime est impuissant auprès de son génie, \\ Et l'univers le place au rang des plus grands Rois ${ }^{90}$.}

D'autre part, Le Censeur contient une polémique autour de l'Ode à l'empereur de Russie, publiée sous le nom de Bertin d'Antilly et réimprimée dans le Spectateur ${ }^{91}$. Bertin refuse de reconnaître qu'il est l'auteur de ce poème.

L'existence du journal royaliste qui flagellait la France républicaine au moment où les troupes de Napoléon menaçaient l'Allemagne inquiétait les pouvoirs locaux. Le Censeur a été défendu, Bertin d'Antilly arrêté sur ordre du Sénat de Hambourg, et libéré grâce à l'intervention de la cour de Russie. Son collaborateur, le marquis de Mesmon, également protégé par la Russie, était même logé et nourri chez le ministre russe à Hambourg Ivan Mouraviev-Apostol. Ensuite les deux journalistes se sont installés à Saint-Pétersbourg. ${ }^{92}$

\section{Mercure de France}

Au tout début du XIX ${ }^{\mathrm{e}}$ siècle, les émigrés commencent à retourner en France. D’après le témoignage du marquis de La Maisonfort : "Les émigrés, ruinés depuis si longtemps, avaient la rage de s'achever, en rentrant racheter leurs biens. La voix della cara patria parlait plus haut que la raison ${ }^{93}$. On avait besoin plus qu'avant d'informations sur la France. En réponse à de telles humeurs Fauche réimprime, entre 1800 et 1802, le célèbre périodique parisien Mercure de France. Journal historique, politique et littéraire. Il annonce que « le Journal paraitra le $1^{\mathrm{er}}$ et le 15 de chaque mois dans le format in $-8^{\circ}$ et par cahiers de cinq feuilles chacun $»{ }^{94}$. Cette nouvelle version, à la différence de la publication

${ }^{88}$ Deutsche Presse, Bd. 1 : Hamburg, op. cit., n ${ }^{\circ}$ 782, S. 629-630 ; https://books.google.ru : Le Censeur, journal politique et littéraire.

${ }^{89}$ Le Censeur, $1800, \mathrm{n}^{\circ}$ 6, 22 février ; ${ }^{\circ} 7,1$ mars ; $\mathrm{n}^{\circ} 12,5$ avril ; ${ }^{\circ} 13,12$ avril.

${ }^{90}$ Le Censeur, $1800, \mathrm{n}^{\circ} 4,8$ février.

${ }^{91}$ Le Censeur, $1800, \mathrm{n}^{\circ}$ 6, 22 février.

92 Матвей И. Муравьев-Апостол, «Из рассказов Матвея Ивановича Муравьева-Апостола », сообщ. А.П. Сазанович, Русский архив [Matveї I. Mouraviev-Apostol, «D’après les récits de Matveї Ivanovitch Mouraviev-Apostol », Archives russes], 1888, livre 3, fasc. 11, p. 369-372.

${ }^{93}$ Antoine-Philippe de La Maisonfort, marquis de, Mémoires d'un agent royaliste sous la Révolution, l'Empire et la Restauration 1763-1827, Paris, Mercure de France, 1998, p. 239.

${ }^{94}$ Mercure de France, journal historique, politique et littéraire, réimpression de Brunswic, chez Pierre François Fauche et Comp. 1800-1802; voir Deutsche Presse, op. cit., Bd. 3, Presse der Regionen 
originale, comporte parfois des notes des éditeurs de Brunswick. On fait même l'échange des matériaux. Le Mercure reproduit des articles publiés dans le Spectateur, Baudus livre ouvertement ses écrits au périodique parisien.

La section Politique extérieure de ce journal propose régulièrement des informations « russes ». Au moment de l'amélioration des liens entre la République et l'Empire, on publie dans plusieurs cahiers des textes développés consacrés à la Russie. On explique l'actualité de telles publications: "Tous les regards sont tournés aujourd'hui vers cet empire qui a commencé avec le dix-huitième siècle, et qui s'avance à grands pas vers ce haut degré de puissance et d'éclat que lui promettent depuis longtemps les prophéties de la plus sage politique " ${ }^{95}$. Le journal publie "quelques tableaux de la population et de l'empire russe [...] prises sur les états les plus authentiques »: «Dénombrement des hommes qui ont payé la capitation en Russie, en 1755 », « Etat des revenus de l'Empire de Russie, année 1778 », «Etat de dépenses de l'Empire de Russie. Année 1778 », « Tableau du militaire de Russie, suivant l'état envoyé en $1778 »{ }^{96}$

Comme faisant suite à cette série de documents, le journal publie, dans un cahier daté du 21 avril 1801, une notice rédigée par un auteur anonyme qui se présente ainsi : «En lisant, dans le Mercure, les articles de statistique sur l'Empire de Russie, j'ai recherché les notions qu'un voyage entrepris, il y a peu d'années, dans ce vaste pays, m'avait à portée de recueillir ». Dès le début, l'auteur insiste sur l'importance des réformes de Pierre le Grand : «Avant Pierre I ${ }^{\mathrm{er}}$, cet empire gémissait sous l'ignorance et la barbarie. Il fallut le génie de ce prince pour surmonter le caractère de sa nation ; encore ne finit-il pas son ouvrage : et, malgré tous les soins que ses successeurs se sont donnés, ils n'ont pu effacer toutes les traces de l'ancienne barbarie ».

Les chapitres qui suivent contiennent des observations sur des aspects différents: Mœurs («Le servage existe toujours en Russie». "Aucun peuple ne dissimule ses sentiments aussi bien que le russe ») ; Population («A Moscou les mœurs sont différents ; le luxe asiatique y domine, et les manières européennes sont seules en usage à Pétersbourg ») ; Religion ( «Pierre $\mathrm{I}^{\mathrm{er}}$, qui s'aperçut que l'autorité du patriarche balançait la sienne et pourrait lui devenir nuisible, abolit cette dignité, se déclara chef de l'église, et établit un tribunal appelé le Saint Synode, qui est présidé par un archevêque ») ; Sciences et éducation («Le peuple était très-ignorant, mais en général les enfants apprennent aujourd'hui à lire, à écrire et à compter») ; Gouvernement (« La constitution russe a revêtu le prince, de la même autorité sur la nation, que le père a sur ses enfants. Toute la puissance réside dans la personne du czar». "Les lois furent réformées, comme les mœurs, par Pierre-le-Grand. Le code barbare qui existait avant lui éprouva des changements considérables, dès le règne d'Alexis, père de Pierre. La police est exacte et sévère en Russie. Elle y est faite, presque partout, à coup de canne et de knout. Les coupables sont exilés en Sibérie, où leur existence devient utile par les travaux auxquelles ils sont assujettis. Les voleurs travaillent, toute leur vie, aux fortifications ou à d'autres ouvrages pénibles »). On conclut ce dernier chapitre par des remarques favorables sur la personne et sur la politique de Paul $\mathrm{I}^{\mathrm{er}}$ qui « a rendu un bel hommage à la vertu de son épouse, en lui donnant la direction suprême de tous les établissements de bienfaisance. L’impératrice répond parfaitement aux vues du czar, et trouve ses plus doux plaisirs dans

Braunschweig / Wolfenbüttel, Hildesheim-Goslar / Britta Berg; Peter Albrecht, Teil 1 (Braunschweig), Stuttgart-Bad Cannstatt, Frommann-Holzboog, 2003, n 178, S. 394-395.

95 Mercure de France, ${ }^{\circ}$ XVI, 16 pluviôse, an 9 (5 février 1801), p. 289.

${ }^{96}$ Mercure de France, $\mathrm{n}^{\circ}$ XVII, I ${ }^{\mathrm{er}}$ ventôse, an 9 (20 février 1801), p. 391 ; n XVIII, 16 ventôse, an 9 (7 mars 1801), p. 453-458. 
les devoirs qui lui sont imposés ${ }^{97}$. Le même cahier du Mercure annonce la mort du czar : « le 25 mars, Paul I ${ }^{\text {er }}$ a été trouvé mort dans son lit, à quatre heure du matin. [...] On ignore les détails d'une mort si subite et si extraordinaire. Voici ce qu'on lit dans le journal officiel du 25 germinal ; Paul Ier est mort dans la nuit du 24 au 25 mars !!! L'escadre anglaise a passé le Sund le 31 !!! L'histoire nous apprendra les rapports qui peuvent exister entre ces deux événemens !!! ${ }^{98}$. Le cahier du 6 mai insère les chapitres suivants de la notice consacrée à la Russie traitant de: Industrie et Commerce; Commerce français en Russie, par la mer Baltique et par la mer Noire ; Commerce anglais en Russie ; Revenus et finances ; Etat militaire ${ }^{99}$.

\section{Les sources d'information des journaux des émigrés}

D'après les périodiques eux-mêmes, les émigrés ont des contacts avec leurs compatriotes en France, ils connaissent bien la presse parisienne, insèrent souvent des extraits de journaux français, notamment vers la fin du Spectateur, les cas de réimpression du Mercure de France le confirment également. Les journalistes sont en correspondance avec leurs compatriotes réfugiés en Angleterre et diffusent même des journaux de Londres. Par exemple, le Journal d'Altona annonce la parution du périodique londonien Paris pendant l'année de 1795 publié par Jean-Gabriel Peltier ${ }^{100}$. Simon Burrows a démontré les liens de Fauche et de La Maisonfort avec Mallet du Pan, rédacteur du Mercure Britannique ${ }^{101}$.

Les contacts des journalistes et des éditeurs avec la Russie sont réguliers et variés. Baudus lui-même est bien informé des affaires russes ${ }^{102}$. Ainsi, dans sa correspondance avec Talleyrand, il cite plusieurs de ses sources : diplomates russes, émigrés, négociants anglais, journalistes de Hambourg, gazettes allemandes et hollandaises, etc. ${ }^{103}$ Parmi ses connaissances russes, la personne du ministre à Hambourg, Ivan Matvéevitch MouravievApostol, est la plus importante. Mouraviev et sa femme suivaient attentivement les nouveaux cahiers du Spectateur, ils recevaient des livres de Fauche par l'intermédiaire de Baudus, discutaient avec lui des nouveautés de la librairie française, etc.

Baudus cite souvent le nom de Mouraviev dans ses relations à Talleyrand, grâce au diplomate russe, il peut connaître des informations politiques précieuses. Il n'est pas exclu que Mouraviev ait eu de l'influence sur le contenu de certaines publications concernant la Russie. Baudus à son tour pouvait lui fournir des renseignements du monde de l'émigration, donc cet échange était réciproquement utile.

Éditeur de plusieurs journaux des émigrés, Pierre-François Fauche se rend en visite dans l'Empire plus d'une fois. Ses échanges avec la Russie se développent certainement à l'occasion de son voyage de plusieurs mois, effectué au début de l'année 1798 et annoncé dans le Spectateur: "Le sieur Fauche cherche un compagnon de voyage pour aller en

\footnotetext{
${ }^{97}$ Mercure de France, $\mathrm{n}^{\circ} \mathrm{XXI},{ }^{\mathrm{er}}$ floréal, an 9. (21 avril 1801), p. 209-216.

${ }^{98}$ Mercure de France, $\mathrm{n}^{\circ} \mathrm{XXI},{ }^{\mathrm{er}}$ floréal, an 9. (21 avril 1801), p. 235-236.

${ }^{99}$ Mercure de France, ${ }^{\circ}$ XXII, 16 Floréal, an 9 (6 mai 18o1), p. 288-289.

${ }^{100}$ Journal d'Altona, $\mathrm{n}^{\circ}$ 26, 30 juillet 1795.

${ }^{101}$ Simon Burrows, French Exile Journalism and European Politics, 1792-1814, London, The Boydell Press, 2000 ; Sur la page de titre du Mercure britannique on peut lire : «Et pour le continent se trouve chez Fauche \& Co. à Hambourg ; \& chez libraires de Vienne, Berlin, Francfort \& Leipsic ».

${ }^{102}$ Флоранс де Бодюс, Владимир А. Сомов, «Амабль де Бодюс, Monsieur le Spectateur du Nord, и его русские знакомства», XVIII век [Florence de Baudus, Vladimir A. Somov, « Amable de Baudus, Monsieur le Spectateur du Nord, et ses connaissances russes », XVIII siècle], fasc. 28, sous la dir. de N.D. Kotchetkova], Moscou, Saint-Pétersbourg, 2015, p. 236-287.

${ }^{103}$ AAE, CP Hambourg, 116.
} 
Russie, par Berlin, Danzig, Königsberg, Memel, Riga, et Pétersbourg. Il partira du 15 au 20 janvier $»^{104}$. De nouveau Fauche visite Saint-Pétersbourg au tout début des années 180o, au moment de la faillite de son entreprise ${ }^{105}$. Les frères Fauche font alors plusieurs tentatives pour s'établir sur ce marché prometteur ${ }^{106}$. Ils adressent successivement aux empereurs Paul $\mathrm{I}^{\mathrm{er}}$ et Alexandre $\mathrm{I}^{\mathrm{er}}$ des mémoires pour demander le monopole de l'importation des livres étrangers, pour organiser en Russie leur imprimerie, mais ces projets ambitieux ne seront pas réalisés. Parmi leurs connaissances russes, il faut citer les diplomates résidant en Allemagne (Doubrovski, Panine, Mouraviev), des personnes proches de la cour impériale (le prince Platon Zoubov, Nicolaï Novossiltsev, le banquier Alexandre Rall, le secrétaire d'Etat Fédor Engel) et bien entendu des libraires de SaintPétersbourg et de $\operatorname{Moscou}^{107}$. Pendant son séjour en Russie, Fauche, grâce à ses connaissances dans le milieu des libraires, pouvait avoir eu des contacts avec Nicolaï Karamzine.

Certains émigrés du cercle du Spectateur séjournent également en Russie. Le marquis de La Maisonfort visite Saint-Pétersbourg en qualité d'agent de Louis XVIII et y est accueilli par Paul I ${ }^{\mathrm{er}}$ (1799). Il remplit différentes missions diplomatiques pour la cour impériale, puis entre au service russe (1804) et il est même nommé ministre plénipotentiaire de Russie auprès du duc de Brunswick (1806). Le marquis de Mesmon et Bertin d'Antilly, après la fermeture de leur journal Le Censeur par décision du Sénat de Hambourg, se réfugient à Saint-Pétersbourg. Le frère de Charles de Villers, l'un de principaux collaborateurs du Spectateur, s'occupe de l'éducation des nobles russes pendant plusieurs années ${ }^{108}$. Le journaliste lui-même, à un moment donné, espérait trouver du soutien en Russie, et il a informé Baudus de cette tentative manquée (le 6 mai 180o). Encore un canal éventuel d'information de Charles de Villers sur la Russie est son amie Dorothea Rodde-Schlözer, la fille du fameux historien de la Russie, membre de l'Académie de science de Saint-Pétersbourg, August-Ludwig Schlözer ${ }^{109}$.

Les archives de Baudus contiennent plusieurs lettres d'émigrés séjournant en Russie. Un correspondant assidu de Baudus est l'abbé Joseph François Marie. Prélat éclairé, il accompagne Louis XVIII dans son exil, réside à Blankenburg, ainsi qu'à Mitau, où l'empereur russe a donné l'asile au roi et à sa cour.

L'abbé discute le contenu des nouveaux cahiers du journal, fait des remarques critiques et donne des conseils, et il évoque constamment l'importance du Spectateur pour les émigrés. Il raconte que « toute la colonie française » est « extrêmement contente » de lire

\footnotetext{
${ }^{104}$ Le Spectateur du Nord, 1797, t. 4 (octobre, novembre, décembre), p. [VI]. Voir également Stadts- und Gelehrte Zeitung des hamburgischen umparteyischen Correspondenten, 1797, $\mathrm{n}^{\circ} 206 ; 1798, \mathrm{n}^{\circ} 8$.

${ }^{105}$ La lettre de Fréderic César La Harpe à l'empereur Alexandre I ${ }^{\mathrm{er}}$ (le 19 décembre 1801), Correspondance de Fréderic-César de La Harpe et Alexandre I ${ }^{\text {er }}$ suivie de la correspondance de F.-C. La Harpe avec les membres de la famille impériale de Russie, publ. par Jean Charles Biaudet et Françoise Nicod, Neuchatel, 1978, t. I, p. 377. ${ }^{106}$ Vladimir Somov, «La librairie française en Russie au XVIII ${ }^{\mathrm{e}}$ siècle », Est-Ouest : Transferts et réceptions dans le monde du livre en Europe (XVII $-X X^{e}$ siècles), éd. par F. Barbier, Leipzig, Leipziger Univesitätsverlag, 2005, p. 107.

${ }^{107}$ Vladimir A. Somov, «Pierre François Fauche, l'imprimeur-libraire européen et ses catalogues », art. cit., p. $82-87$.

${ }^{108}$ Dmitri A. Goutnov, «Frédéric Villers entre deux France : Un émigré royaliste chef de la police de Napoléon à Moscou ", L'influence française en Russie au XVIII siècle, publié sous la direction de Jean-Pierre Poussou, Anne Mezin \& Yves Perret-Gentil, Paris, 2004, p. 481-485; Les Français en Russie au siècle des Lumières : Dictionnaire des Français, Suisse, Wallons et autres francophones en Russie de Pierre le Grand à Paul I ${ }^{e r}$, sous la dir. d'Anne Mezin \& Vladislav Rjéoutski, Ferney-Voltaire, CIEDS, 2011, t. 2, p. 825-826.

${ }^{109}$ August Ludwig Schlözer, Dorothea Schlözer, Münz-, Geld- und Bergwerks-Geschichte des russischen Kaiserthums, vom J. 1700 bis 1789, Vandenhoeck und Ruprecht, Göttingen, 1791.
} 
le Spectateur et le roi l'attend «avec impatience» (le 9 août 1797, le 12 janvier 1799). Ses lettres démontrent l'état d'esprit des émigrés et témoignent de l'atmosphère de peur qui règne parmi eux : "Le rhinocéros révolutionnaire est au-dessus de tout, et sa marche rapide, toute lourde qu'elle est, doit effrayer déjà la Sibérie, le Groenland et le Tibet » (le 21 décembre 1797).

L'abbé informe Baudus des contacts que des émigrés ont avec les pouvoirs russes. Le 27 octobre 1797, il écrit de Blankenburg que le prince Condé « se propose d'aller droit à Pétersbourg, où des grâces et des dons de tous les genres l'attendent » et il salue la générosité de la cour impériale.

Marie évoque régulièrement la Russie pendant son séjour à Mitau. Les émigrés gardent le sentiment de la reconnaissance envers l'empereur russe. L'abbé écrit le 18 août 1799 : « Il [Paul I $\left.{ }^{\mathrm{er}}\right]$ marche d'un pas ferme dans sa politique, parce que la justice et l'honneur lui servent de base. [...] L'intelligence la plus parfaite règne, dit-on, entre lui et le roi d'Angleterre, et le roi de Suède. Ils entraîneront le reste de l'Europe, et remettront une demi-douzaine de souverains sur le trône, ce qui ne s'est pas vu depuis longtemps.

Dimanche prochain, on lira dans toutes les églises de l'empire russe, de nos parages, l'ample relation des victoires de Souvorov; et prières publiques seront faites avec lecture des grâces multipliées dont Paul $\mathrm{I}^{\mathrm{er}}$ vient de récompenser les braves troupes qui ont combattu si glorieusement en Italie ».

Marie est très attristé par la nouvelle de la mort de Souvorov ainsi que par le changement de politique russe, et il écrit, le 3 juin 1800 : «Aujourd'hui, je viens déplorer avec vous la mort du héros de nos jours. Le prince Italique, le généralissime de Russie, le brave et religieux Souvorov mourut le 19 du mois dernier ${ }^{110}$, à Pétersbourg, dans une espèce de disgrâce. Il ne mappartient pas de juger un si grand procès, mais je pleure sur la tombe de ce grand homme et sur le parti qu'a pris Paul ${ }^{\mathrm{er}}$ de ne plus vouloir avoir rien de commun avec des alliés dont il eut tant à se plaindre ».

Pendant son "glacial séjour » à Mitau, l'abbé souffre du froid et il est surpris de l'endurance des troupes russes : « Le soldat russe ne ressemble point aux autres : il chante en marchant par un froid terrible. Nous eûmes hier, à minuit, $\mathbf{2 2}^{\circ}$ de froid, du thermomètre de Réaumur. Il y a de quoi geler tous les nez, toutes les oreilles, tous les pieds et toutes les mains » (le 4 février 1799). Ses compatriotes supportaient mal le climat de la région et les conditions modestes de la vie quotidienne. Beaucoup de Français sont décédés à Mitau ${ }^{111}$. L'abbé même a trouvé sa mort en Russie dans la ville de Memel au mois de février 1801 dans des circonstances tragiques. Après que la cour royale ait dû quitter Mitau sur l'ordre de Paul $\mathrm{I}^{\mathrm{er}}$, qui avait entrepris un rapprochement avec la République française, Joseph François Marie s'est suicidé, bouleversé par la menace de nouvelles errances.

\section{Les journaux des émigrés en Russie}

Les périodiques « allemands » créés par des émigrés étaient connus en Russie, grâce à l'activité des libraires et aux contacts « russes » des émigrés.

Parfois le contenu des journaux mêmes garde les témoignages de leur diffusion dans la société russe. Par exemple, on lit dans le Journal d'Altona une annonce d'une certaine Agrippine d'Ouchakov adressée à Ivan Ivanovitch Chouvalov :

\footnotetext{
${ }^{110}$ A. Souvorov est mort le 6 (18) mai 1800.

${ }^{111}$ Voir : Les registres des décès de l'église catholique de Mitau. Archives historiques de l'Etat de Lettonie (Latvijas Valsts vēstures arhīvs), fonds 4038, inv. 2, dossier 2216.
} 
« Madame Agripine Duchacoff avertit Monsieur de Schouvaloff, Grand-Chambellan de Russie, que la Lettre-de-change de mille Roubles qu'il doit, dont le terme expirera au mois de Décembre de cette année 1795, lui a été volée. La dite Dame en ayant informé plusieurs fois par écrit S. E. ; mais n'ayant eu aucune réponse, et dans la crainte que ses lettres ne soient pas parvenues, elle a pris le parti, sachant que Mr. de Schouvaloff lit toutes les Gazettes Françoises, de l'instruire par cette voie, et de le prier de ne remettre le payement qu'à elle-même $»^{112}$.

Les exemplaires des périodiques des émigrés conservés dans les grandes bibliothèques russes confirment leur présence dans les collections privées de l'époque. Ainsi, on trouve à la Bibliothèque Nationale de Russie des volumes du Réveil appartenant au comte Alexandre Sergueevitch Stroganov ${ }^{113}$.

La destinée « russe » du «Spectateur du Nord » se confirme d'après plusieurs sources : la documentation de la censure impériale, les catalogues des libraires, les inventaires des bibliothèques $^{114}$, les traductions dans les périodiques russes ${ }^{115}$, les correspondances de l'époque, etc. En 1797 on pouvait s'abonner au Spectateur chez plusieurs libraires à SaintPétersbourg et à Moscou ${ }^{116}$. Au début du mois de mai 1798 le journal officiel de la capitale, Sankt-Peterbourgskie Vedomosti, déclare que le bureau de poste propose la souscription au «journal français» Le Spectateur du Nord, publié à Hambourg ${ }^{117}$. C'était juste le moment où Fauche effectuait son voyage commercial en Russie. Plus tard, en 180o, le catalogue du libraire pétersbourgeois Hermann Klostermann, qui est un des partenaires de Fauche, propose une série complète du Spectateur de l'année 1798, « 12 cahiers pour 12 roubles ${ }^{118}$.

Les entrées en Russie des cahiers du Spectateur du Nord et du Journal littéraire et bibliographique sont enregistrées dans les archives censoriales. On apprend que les

\footnotetext{
${ }^{112}$ Journal d'Altona, $\mathrm{n}^{\circ}$ 111, 6 novembre 1795.

${ }^{113}$ Le Réveil, ouvrage périodique, moral et littéraire, 1798-1799, t. 1-3 (RNB côte : 16.54.3.1)

${ }^{114}$ L'inventaire après décès de la bibliothèque privée de Piotr Doubrovski contient de nombreux ouvrages d'émigrés, dont ceux produits par la maison «Pierre François Fauche E Cie. », par ex., une série presque complète du « Spectateur du Nord» pour les années 1797-1798. Voir RNB, ms, Fr. F XVIII № 21, fol. 13-14.

${ }^{115}$ Voir par ex. Сводный каталог сериальных изданий в России (1801-1825) [Catalogue collectif des éditions sérielles en Russie (1801-1825)], Saint-Pétersbourg, 1997-2015, t. 1-4 ; Наталья Д. Кочеткова, «Меланхолия' Ж. Делиля: Подражание Н.М. Карамзина и перевод П.Ю. Львова», Чтения отдела русской литературы XVIII века, вып. 7 (М. В. Ломоносов и словесность его времени. Перевод и подражание в русской литературе XVIII века) [Natalia D.Kotchetkova, "'La Mélancolie' de J. Delille : L'imitation de N.M. Karamzine et la traduction de P.Ju. Lvov ", Les conférences du département de la littérature russe du XVIII siècle, fasc. 7 (M.V. Lomonossov et les lettres de son temps. La traduction et l'imitation dans la littérature russe du XVIII ${ }^{e}$ siècle), sous la dir. d'A.A. Kostine et O.A. Demine], Moscou ; Saint-Pétersbourg, 2013, p. 209-218 ; Вадим Д. Рак, «Библиографические заметки», XVIII век [Vadim D. Rak, «Les notes bibliographiques », XVIII siècle], fasc. 28, sous la dir. de N.D. Kotchetkova, Moscou ; Saint-Pétersbourg, 2015, p. 317-321.

${ }^{116}$ Владимир А. Сомов, «Французская книга в русской цензуре конца XVIII века », Цензура и статус печатного слова во Франции и России эпохи Просвещения. Век Просвещения [Vladimir A. Somov, « Le livre français dans la censure russe de la fin du XVIII siècle », Censure et statut de l'imprimé en France et en Russie au Siècle des Lumières. Le Siècle des Lumières], sous la dir. de S.Ja. Karp et al., t. 2, Moscou, 2008, p. 176.

${ }^{117}$ Sankt-Pétersbourgskie Vedomosti, 4 mai 1798, $\mathrm{n}^{\circ} 36$.

${ }^{118}$ Catalogue de livres françois, latins, italiens et anglois de Klostermann, Saint-Pétersbourg, de l'Imprimérie Impériale, 180o, p. 154.
} 
numéros annonçant des ouvrages français sur Catherine II (Rulhière, Castéra) sont bloqués par les censeurs ${ }^{119}$.

L’abbé Marie témoigne plus d'une fois des difficultés de la réception en Russie du journal si attendu par les Français. En comparaison avec Blankenburg, où les émigrés reçoivent Le Spectateur en quelques jours, les envois de Hambourg arrivent à Mitau lentement, parfois avec un retard de quelques mois. Outre cela, il existe le risque que les livres soient saisis par la douane russe. Le bureau de censure installé à Riga d'où les imprimés étrangers arrivaient à Mitau avait la renommée d'être le plus énergique et le plus sévère.

Les émigrés inventent toutes sortes de ruses pour éviter le contrôle. Marie expose son plan à Baudus :

«La rigueur des prohibitions est telle dans le pays que nous habitons, qu'il ne nous est pas possible de faire arriver un livre, même de prières, sans les soumettre à la censure la plus vigilante. Votre journal n'aurait point échappé aux inquisiteurs, tout nourri qu'il est des vrais principes de l'ordre social. Ainsi, lorsque vous aurez la volonté de m'en transmettre quelques $\mathrm{n}^{\circ}$, donnez-lui, comme aux autres, la forme d'un paquet simplement épistolaire, et envoyez-le à Ch. de Thauvenay ${ }^{120}$, qui saura bien nous le faire parvenir par quelque courrier, ou par quelque autre voyageur» (12 janvier 1799). Le contrôle des livres devient avec le temps de plus en plus sévère. Le 17 mars 1800 l'abbé écrit : " Nous ne pouvons pas ici nous servir de la poste pour recevoir votre journal, parce que la censure de Riga arrête tout et le garde jusqu'à ce qu'un examen, souvent fort long, ait convaincu les censeurs qu'il n'y a point d'inconvénient à laisser circuler tel ou tel ouvrage. Mais comme on est très chatouilleux sur l'article, dans ces parages voisins de la frontière, les inconvénients de pareilles circulations grossissent souvent au microscope de la censure. [...] Nous n'avons que la triste ressource d'une petite contrebande ».

Après la parution de l'oukase de Paul I ${ }^{\mathrm{er}}$ qui défend totalement l'importation des livres étrangers (avril 180o) l'abbé écrit : « Des ordres nouveaux, émanés dit-on, de l'empereur défendent toute espèce d'importation de livres, dans les états russes. Ainsi, nous voilà réduits bientôt à la seule gazette [...]. Si vous nous gratifiez des numéros suivants, il faut bien prévenir $M$. de Thauvenay de ne les envoyer que sous la forme de paquets de correspondance, ou dans la poche de quelque voyageuse, car celles des voyageurs et courriers ordinaires ne sont point à l'abri des fouilles des inquisiteurs postés à la frontière » (le 3 juin 1800 ).

Mais le 18 décembre 1800 il annonce une bonne nouvelle : "Par un ukase nouveau, dont vous aurez eu connaissance sans doute, votre journal, Monsieur, est du nombre de ceux qui furent exceptés de la proscription générale il y a environ deux mois. Ainsi, vous ferez un vrai plaisir au chef de notre colonie lorsque vous nous gratifierez de quelquesuns de vos numéros ${ }^{121}$.

Les autres émigrés témoignent de la renommée du Spectateur. Ainsi, l'abbé Tressan écrit à Baudus de Leipzig, que son journal est connu dans le milieu diplomatique, y compris du ministre russe Panine (30 avril 1798). En se déplaçant à Saint-Pétersbourg, l'abbé annonce, le 8 avril 1799: «Au reste, je n'entends jamais parler de vos ouvrages qu'avec les éloges les plus sincères et les plus complets. J'entends dire généralement c'est

\footnotetext{
${ }^{119}$ Владимир А. Сомов, «Французская книга в русской цензуре конца XVIII века », art. cit., p. 178, 185, 190.

${ }^{120}$ L'agent de la cour royale à Hambourg.

${ }^{121}$ On ne mentionne pas cet oukase dans les études sur l'histoire de la censure russe, mais il y avait effectivement des exceptions pour certaines personnes et certains ouvrages. Voir Владимир А. Сомов, « Французская книга в русской цензуре конца XVIII века », art. cit., p. 165-167.
} 
le premier et le meilleur des journaux. Vous devez avoir eu des nouvelles demandes de ce pays-ci. Je vous ai acquis quatre à six lecteurs de plus qui ont dû s'abonner, et ce nombre augmentera tous les jours. Il se fait ici un petit journal, mais l'auteur qui n'a pas vos ressources attend modestement vos numéros et les donne par extraits. C'est un écho du vôtre. Heureux quand il ne fait que vous répéter. J'ai trouvé la même opinion partout où nous avons été. Je prévois qu'il en sera de même partout où nous irons encore ».

\section{Journal littéraire de Saint-Pétersbourg}

« Un petit journal » défini par l'abbé Tressan comme "un écho » du Spectateur est le Journal littéraire de Saint-Pétersbourg, créé par un jeune Français, le chevalier de Gaston.

Marie-Joseph Hiacynthe Gaston de Pollier, dit chevalier de Gaston, était connu surtout pour sa traduction de l'Enéide. Ancien officier du régiment des chasseurs du Gévaudan, il vient en Russie par Hambourg, grâce au soutien de son oncle, l'abbé Gaston, séjournant en Allemagne, et du marquis de La Maisonfort ${ }^{122}$. Il s'installe à Saint-Pétersbourg probablement vers 1794. Lorsqu'il revient en France en 1801, il essaye de se faire rayer de la liste des émigrés et prétend avoir quitté sa patrie avant la Révolution. Il déclare qu'il était parti « au mois de juin de l'année 1787 pour voyager dans les cours du Nord, et pour y étudier les arts et la diplomatie à laquelle il se destinait. [...] Les malheurs successifs de sa famille, et la mort d'un père octogénaire qui périt dans les cachots victime du règne de la terreur, lui ôtèrent jusqu'à l'espoir de revoir jamais ses foyers. Dès ce moment, il chercha un asile à Saint-Pétersbourg où les moyens littéraires furent pendant huit ans son unique ressource ». Gaston produit plusieurs attestations à l'appui de sa déclaration, mettant à profit ses connaissances dans les hautes sphères de la société russe. Sa demande est même appuyée par l'ambassadeur de la cour impériale Markov. Le général Sprengporten, qui s'est occupé de la libération des prisonniers russes en France, certifie « avoir connu le pétitionnaire vivant en Russie de littérature dès 1788 (sic! - V. S.) ». Un jeune aristocrate russe le prince Mikhaïl Petrovitch Dolgorouki, responsable de la même affaire diplomatique ${ }^{123}$, atteste qu'il a rencontré Gaston «à Saint-Pétersbourg depuis l'année 1794 jusqu'en $1800^{124}$ ».

Dans la capitale russe, Gaston trouve un protecteur, le comte Nicolaï Petrovitch Roumiantsev, homme d'État et mécène, ancien diplomate en Allemagne, ministre à Francfort, responsable des missions importantes auprès des émigrés. D’après les rumeurs, c'est Roumiantsev qui incite Gaston à créer un périodique francophone. Le Journal Littéraire de Saint-Pétersbourg paraît dans l'imprimerie du Corps des Cadets deux fois par mois durant trois années, entre 1798 et 1800 . Consacré d'abord et surtout aux belles lettres, ce bimensuel traite des littératures française, allemande, anglaise, et un peu russe. On y trouve plusieurs traductions d'auteurs de l'Antiquité, grecque et latine. Une place importante est réservée à la littérature française de toutes les époques, du Moyen Âge au Siècle des Lumières, et avant tout à Voltaire ${ }^{125}$. La littérature anglaise, surtout les romans,

\footnotetext{
${ }^{122}$ Petr R. Zaborov, « Le Journal littéraire de Saint-Pétersbourg et les échanges culturels entre la Russie et l'Europe ", Réseaux de l'esprit en Europe des Lumières au XIX ${ }^{e}$ siècle. Actes du Colloque international de Coppet réunis par Wladimir Berelowitch et Michel Porret, Genève, 2009, p. 203-215; Antoine Philippe, marquis de La Maisonfort, Mémoires d'un agent royaliste, op. cit., p. 199.

${ }^{123}$ Charles Corbet, A l'ère des nationalismes : L'opinion française face à l'inconnue russe (1799-1894), Paris, Didier, 1967, p. 40.

${ }^{124}$ Archives nationales, F/7/4899/19278.

${ }^{125}$ Petr R. Zaborov, art. cit., p. 208-212.
} 
est beaucoup appréciée, et on publie des articles sur plusieurs auteurs allemands. Bien que Gaston affirme à plusieurs reprises se tenir à l'écart des questions politiques, le journal des émigrés ne peut pas rester indifférent à la révolution, aux campagnes militaires, etc. Une large place est donnée aux annonces des livres nouveaux (les comptes rendus, les catalogues, etc.). La plupart des textes ne sont pas signés, on peut supposer qu'ils sont rédigés par Gaston lui-même et par ses compatriotes.

Nous n'avons pas de renseignements sur le lectorat de ce journal, néanmoins on peut facilement délimiter le milieu dans lequel il est diffusé par l'audience qu'il vise. Il s'adresse aux réfugiés eux-mêmes et à la haute société russe.

Le Journal Littéraire de Saint-Pétersbourg est créé par un Français pour les Français réfugiés et s'inscrit bien dans la lignée des journaux semblables parus à cette époque à travers l'Europe. On peut supposer que Gaston avait des relations épistolaires avec ses compatriotes restés en France ou établis dans divers pays ${ }^{126}$. Ainsi, au mois de décembre 1799, Gaston annonce la parution à Hambourg du « Nouveau journal français intitulé l'historien de la coalition. M. de Mesmond - Romance, \& M. Bertin d'Antilly, tous deux connus dans la littérature, en sont les rédacteurs. [...]. Il est entrepris dans l'intention de porter les derniers coups à la tyrannie républicaine ${ }^{127}$. Gaston a pu rencontrer ces deux journalistes à Hambourg ainsi qu'à Saint-Pétersbourg, où ils trouvèrent refuge plus tard.

Le jeune Français avait des contacts avec le Spectateur. Son oncle, l'abbé Gaston, est une ancienne connaissance d'Amable de Baudus. Le 5 novembre 1799 de Münster, l'abbé a envoyé à Baudus deux ouvrages poétiques de son neveu: Epitre à la boëte aux suppliques $^{128}$ et Ode pour la fête de S. M. l'empereur ; sur le succès de ses armes en Italie ${ }^{129}$. Dans sa lettre il raconte les succès de son neveu et fait des éloges de la justice et de la modestie de Paul $\mathrm{I}^{\mathrm{er}}$ :

Sa Majesté l'empereur de Russie parût très satisfaite. Par son ordre, 500 exemplaires ont été envoyés dans ses gouvernements. Quant à l'épître, S.M.I. en a, de son propre mouvement, fait faire plusieurs copies, qu'il a fait circuler partout. Cette Boëtte, comme vous le savez sans doute, est un tronc qui est au palais, et en tout temps, le riche comme le pauvre, le Russe et l'étranger, peuvent y déposer leurs suppliques pour S.M.I. qui tous les jours en a les extraits d'après lesquels la grâce est accordée ou refusée. Mon neveu a cru devoir célébrer une si belle institution, et pour que l'éloge fût plus délicat, il n'a jamais parlé qu'à la Boëtte, ce qu'il fallait avec un prince aussi modeste. L'hommage de l'ode à S.M.I. intéresse toute l'Europe. Je vous prie, Monsieur, d'avoir la bonté d'insérer dans votre journal les deux petits ouvrages.

Ces textes ne furent pas acceptés par Baudus, il ne les a probablement pas appréciés, ou bien il a appréhendé la réaction de Saint-Pétersbourg, mais plus tard, après son retour

\footnotetext{
${ }^{126}$ Annet Volmer, Presse und Frankophonie im 18. Jahrhundert. Studien zur französischsprachigen Presse in Thüringen, Kursachsen und Rußland, Leipzig, Leipziger Universitätsverlag, 2000 ; Petr R. Zaborov, art. cit., p. 204.

${ }^{127}$ Journal littéraire de Saint-Pétersbourg (infra - en abrégé JLSPb), 1799, 1 décembre, $\mathrm{n}^{\circ}$ 11, p.40-41. Probablement ce projet éditorial ne s'est pas réalisé. Voir : Deutsche Presse, Bd. 1 : Hamburg, op. cit., S. 1634, $\mathrm{n}^{\circ} 786$.

${ }^{128} J L S P b, 1799,15$ octobre, $n^{\circ} 8$, p. 44-45.

${ }^{129} \mathrm{JLSPb}, 1799, \mathrm{1}^{\mathrm{er}}$ août, ${ }^{\circ}$ 3, p. 21-25. Il existe une édition séparée : Ode à sa Majesté l'empereur sur le succès de ses armes en Italie, St. Pétersbourg, de l'imprimerie impériale, 1799. Voir : Сводный каталог книг на иностранных языках, изданных в России в XVIII веке. 1701-180о. [Catalogue collectif des éditions en langues étrangères imprimées en Russie au XVIII siècle, 1701-18oo], Leningrad, 1984, t. 1, nº 1043 ; JLSPb, 1799, $1^{\mathrm{er}}$ août, $\mathrm{n}^{\circ}$, p. 21-25.
} 
en France, le chevalier de Gaston envoie ses écrits au Spectateur ${ }^{130}$, et ses traductions au Mercure de France ${ }^{131}$, réimprimé par Fauche.

A part les émigrés, ce sont les nobles russes qui s'intéressent au périodique francophone ${ }^{132}$. On ne connaît pas les noms des personnes qui se sont abonnés au Journal Littéraire de Saint-Pétersbourg, mais on peut confirmer cette supposition par les renseignements sur la diffusion de l'Enéide dans la traduction de Gaston, publiée à SaintPétersbourg en 1796, à la fin du règne de Catherine II. Le traducteur a été généreusement récompensé, il a reçu de la part de l'impératrice 440 roubles et une tabatière estimée à 375 roubles $^{133}$. La liste des souscripteurs insérée à la tête de cet ouvrage contient les noms de 74 personnes, qui ont demandé plus de 100 exemplaires. Cette liste s'ouvre par le nom du petit-fils de l'impératrice, le grand-duc Constantin, des grandes duchesses (ses sœurs) et le dernier favori de Catherine, Platon Zoubov. Suivent, dans l'ordre alphabétique, les autres souscripteurs: princes, comtes, ambassadeurs étrangers, diplomates russes, par exemple, le protecteur de Gaston, le comte Nicolaï Roumiantsev, alors «ministre à Francfort », qui a commandé six exemplaires, le comte Alexandre Bezborodko, " ministre des affaires étrangères », cinq exemplaires. On y voit des chambellans, des gentilshommes de chambre, des généraux, des brigadiers, etc. Parmi les souscripteurs, on trouve des femmes, quatre grandes-duchesses et six dames de Saint-Pétersbourg, dix personnes au total. Ce document témoigne des connaissances importantes et étendues du chevalier de Gaston dans la société russe, et même à la cour impériale. On pourrait s'étonner de l'absence presque totale de noms français, mais les émigrés ruinés ne pouvaient pas subventionner de telles publications. D'autre part, comme l'explique le traducteur, « on ne peut pas répondre de l'exactitude de cette liste pour laquelle on s'en est rapporté à des habitants du pays. Plusieurs Souscripteurs n'ont pas voulu donner leurs noms, \& s'il y en a d'autres qui se plaignaient d'avoir été oubliés, ce n'est pas la faute de l'Auteur ${ }^{134}$.

On ne connaît pas l'imprimerie dans laquelle le livre a été fabriqué, mais on voit les noms des libraires qui se chargent de diffuser cet ouvrage :

À Saint-Pétersbourg, à Moscou \& à Vienne chez les frères Gay.

À Riga, chez M. Hartknoch.

À Berlin, chez M. Viegweg le jeune.

À Hambourg, chez M. Fauche.

À Leipsic, chez M. Alici.

À Bâle, chez M. Thurneyzen.

À Londres, chez M. Edwards.

\footnotetext{
${ }^{130}$ H. de Gaston, «Hymne d'un convalescent au soleil. Par le Ch[evalie]r de Gaston », Le Spectateur du Nord, 180o, août, p. 186-187 ; H. de Gaston, «L'Homme de lettre dans la société », Le Spectateur du Nord, 1802, novembre, p. 240-245.

${ }^{131}$ H. de Gaston, «Imprécations de Didon mourante. Fragment d'une nouvelle traduction en vers, par le C. Hyacinthe Gaston », Mercure de France, n²4, 16 Prairial, an 9 (5 Juin 1801), p. $401-404$.

${ }^{132}$ On trouve à la Bibliothèque de l'Académie des sciences de Russie (Saint-Pétersbourg) quelques cahiers $\mathrm{du} J L S P b$ provenant de la bibliothèque des comtes de Vorontsov. Les cahiers du ${ }^{\text {er }}$ novembre et du $1^{\text {er }}$ décembre de l'année 1798 portent sur la couverture une note à l'encre noire : «M. le Cte de Waronzoff » (sic! - V.S.).

${ }^{133}$ Archives historiques d'Etat de Russie (RGIA, Saint-Pétersbourg), fonds 468, inv. 1, part. 2, dossier 3911, fo $199 v, 226 v$.

${ }^{134}$ Traduction en vers des six premiers livres de l'Énéide d'un Poëme sur les Quatre Ages de la Femme E de quelques pièces détachées. Première livraison. Par le ch. de Gaston, Saint-Pétersbourg, 1796, p. [I-IV].
} 
Dans cette liste qui témoigne des contacts de Gaston dans le milieu des libraires, il faut signaler notamment deux noms : Fauche, qui est bien connu, et Alici. Pierre Alici (Alicy), un Français, né à Lunéville, a résidé successivement à Varsovie, à Leipzig et finalement s'est installé à Saint-Pétersbourg ${ }^{135}$. Il est le principal fournisseur des livres annoncés dans le Journal Littéraire de Saint-Pétersbourg et contribue probablement à la création du journal. Le nombre de ses annonces dépasse largement celui des autres libraires annonçant leurs livres dans ce journal (Rospini, Riss et Sausset, Bouvat).

Au cours de son existence, le Journal Littéraire de Saint-Pétersbourg propose aux lecteurs quelque 300 nouveautés. La quasi-totalité des ouvrages est en français. On annonce des livres parus en France, en Russie, en Angleterre et en Allemagne. On peut supposer que la part de ces derniers est la plus importante : les événements politiques rendaient difficile l'envoi des imprimés de France ; en outre, la censure établie à l'égard des ouvrages étrangers vise particulièrement ceux venant de France. Le Journal Littéraire cite plusieurs ouvrages édités ou réimprimés par Fauche qui les avait certainement envoyés à Saint-Pétersbourg.

Les périodiques francophones " allemands » et surtout Le Spectateur du Nord, sont les principales sources d'informations du Journal Littéraire de Saint-Pétersbourg. On y voit les mêmes sujets, les mêmes textes, parfois les mêmes auteurs. Les écrits des mêmes émigrés (de La Maisonfort, Chênedollé, Rivarol, etc.) y sont publiés. Par sa forme, le Journal Littéraire de Saint-Pétersbourg ressemble beaucoup à la revue de La Maisonfort, L'Abeille, les deux suivent le modèle du Mercure de France ${ }^{136}$. La différence entre ces publications « allemandes » et le journal de Gaston réside dans l'absence, chez lui, de sujets politiques, y compris d'informations concernant la Russie. Gaston déclare : "Je me suis interdit la politique ${ }^{137}$. Plusieurs livres ne peuvent alors pas être mentionnés du fait de la censure stricte établie en Russie. C'est ce qui fait l'importance du Journal Littéraire de SaintPétersbourg, qui donne une large place aux livres français, mais c'est aussi ce qui détermine sa destinée. Le dernier numéro est daté du 15 avril 18oo, c'est précisément au mois d'avril que l'importation des livres étrangers est totalement interdite par l'empereur. L'entreprise du chevalier de Gaston perd donc sa raison d'être.

Les publications consacrées à la Russie ne sont pas nombreuses dans ce journal : des œuvres poétiques du rédacteur lui-même, consacrées à des personnages de la cour impériale, des extraits du poème de Bertin d'Antilly faisant un éloge à Paul I ${ }^{\mathrm{er}}$ et empruntés au Spectateur ${ }^{138}$, le compte rendu du Voyage en Russie de Swinton ${ }^{139}$, la traduction d'une chanson russe de Nélédinski-Meletski ${ }^{140}$.

\footnotetext{
${ }^{135}$ Les Français en Russie au siècle des Lumières, op.cit., t. 2, p. 9 ; Archives diplomatiques (Nantes), fonds de l'ambassade française à Saint-Pétersbourg, 599 PO/1/19.

${ }^{136}$ Владимир А. Сомов, «Пресса французских эмигрантов (Гамбург, Брауншвейг, Санкт-Петербург)», Триста лет печати Санкт-Петербурга: Материалы международной научной конференции, СанктПетербург, 11-13 мая 2011 года [Vladimir A. Somov, «Presse des émigrés français (Hambourg, Brunswick, Saint-Pétersbourg) », Trois cents ans de la presse à Saint-Pétersbourg. Actes du colloque international. SaintPétersbourg. Les 11-13 mai 2011], Saint-Pétersbourg, 2011, p. 272.

${ }^{137} J L S P b, \mathrm{n}^{\circ} 3,1$ août 1799, p. 36.

${ }^{138}$ "A Paul I ${ }^{\mathrm{er}}$, Empereur de toutes les Russies. Poeme par M. Bertin d'Antilly », JLSPb, $1799, \mathrm{n}^{\circ} 11,1^{\text {er }}$ décembre, p. 28-36.

139 « Voyage en Russie, en Suéde et en Dannemark en 1788-89-9o et 91. Par Swinton, chez Alici », JLSPb , $1798, \mathrm{n}^{\circ} 4,5$ août, p. 58-59.

${ }^{140}$ «Traduction d'une chanson russe par Mr. de Nélédinsky. Par M. le Cte de Viel ${ }^{* * *}$ », JLSPb, $1798, \mathrm{n}^{\circ}{ }_{1}, 1^{\text {er }}$ juillet, p. 12-13.
} 
Il y a aussi deux traductions des écrits de Karamzine. Ce sont l'idylle Palemon et Daphnis d'après Salomon Gessner (Der Sturm $)^{141}$ et la nouvelle Siera Morena $(1795)^{142}$ sur des motifs espagnols. En général, le traducteur suit avec minutie l'original russe, et il ne défigure pas pour autant le style romantique et pathétique de Karamzine ${ }^{143}$.

\section{Le Journal du Nord}

Pendant le règne d'Alexandre $\mathrm{I}^{\mathrm{er}}$, en 1807 , on entreprend, à Saint-Pétersbourg, l'édition du Journal $d u$ Nord en langue française ${ }^{144}$. Ce périodique officieux est publié par le Ministère des affaires étrangères et le but principal de sa création est de s'opposer à la politique propagandiste de Napoléon. Plusieurs émigrés résidant autrefois à Hambourg et à Brunswick y collaborent. Parmi les créateurs de ce journal se trouvent le marquis de Mesmon et le marquis de La Maisonfort. Pour imprimer le nouveau périodique, un émigré, Alexandre Pluchart, ancien facteur de l'imprimerie de Fauche devenu son rival, est invité de Brunswick et cette invitation est appuyée par le marquis de La Maisonfort. Pluchart apporte d'Allemagne l'équipement de son imprimerie et est suivi par quelques ouvriers. Dans ses contacts avec la Russie, ce libraire suit les traditions de la Maison Fauche, et finalement il réussit à réaliser le projet "russe » de son ancien patron, de s'installer solidement à Saint-Pétersbourg. Le premier rédacteur du Journal du Nord, le comte polonais Jean Potocki, connu comme un écrivain français, est très proche du milieu des émigrés, lui-même ayant résidé dans les années 1794-1796 à Hambourg et à Brunswick $^{145}$. Potocki espère créer un quotidien avec un large réseau de correspondants à l'étranger. En réalité, le Journal du Nord devient un hebdomadaire qui existera cinq ans (1807-1812). Chaque année, environ 50 fascicules in octavo sont publiés. Le périodique comporte des documents officiels de la cour impériale: ordonnances, manifestes, rapports des événements militaires. Les principales rubriques sont les «Nouvelles politiques » (des informations empruntées à la presse étrangère, surtout au périodique parisien «Le Moniteur universel »), et la section "Variétés » où on insère des récits des voyages, des nouvelles des découvertes scientifiques, des évènements du monde des beaux-arts ${ }^{146}$.

\footnotetext{
${ }^{141}$ «Palémon et Daphnis, idyle de m. de Koramzin, traduite par un émigré français », JLSPB, $1798, \mathrm{n}^{\circ} 5, \mathrm{r}^{\mathrm{er}}$ septembre, p. 22-30.

${ }^{142}$ "La Sierra Morena de m. Koramzin ; traduite par un émigré français », JLSPB, 1798, n8, 15 octobre, p. 1626.

${ }^{143}$ Voir par ex. la traduction de la nouvelle Siera Morena : «пламя любви » = « le volcan de l'amour », « кровь его палит меня " « је suis couvert de son sang", «мертвое страшное уединение окружило меня " = la solitude effrayante de la mort m'entourait», «живо восчувствовал я суету всего подлунного » = « je me representais vivement le néant des choses humaines », « хладный мир » = « triste univers ». Le journal annonce que ces deux textes de Karamzine sont traduits par un émigré français. On peut supposer que c'est Gaston lui-même qui savait probablement le russe. Est-ce que Karamzine lui-même participa à ces traductions?

${ }^{144}$ L'index détaillé du Journal du Nord est rédigé par Natalia Vochtchinskaïa (Moscou).

${ }^{145}$ Jean Potocki, CEuvres, éd. par François Rosset et Dominique Triaire, Leuven, Peeters, 2006, t. 3, 439-440 ; t. 5, p. 150, 183, 193, 194, 197, 213 ; Jean Potocki, Lettres à Ernst Théodor Langer, HAB, Ms BA II 110, fol. 179198 ; Voir : Lorenz Frischknecht, «Un hiver pour les livres: Dix lettres de Jean Potocki à Ernst Théodor Langer, bibliothécaire de Wolfenbüttel », Études des lettres, 4, 2012, p. 195-222.

${ }^{146}$ Vladislav Rjéoutski, Natalia Speranskaia, «The Francophone Press in Russia: A Cultural Bridge and an Instrument of Propaganda ", French and Russian in Imperial Russia, vol. 1, Language Use Among the Russian Elite, sous la dir. de Derek Offord, Lara Ryazanova-Clarke, Vladislav Rjéoutski et Gesine Argent, Edimbourg, Edinburgh University Press, 2015, p. 92.
} 


\section{Conclusion}

Les périodiques francophones, créés par des royalistes au Nord de l'Europe, en Allemagne et en Russie (Altona, Hambourg, Brunswick, Saint-Pétersbourg) s'adressent aux réfugiés eux-mêmes et à la haute société des pays de leurs résidences. Les émigrés, grâce à leur origine sociale et à la domination de la langue française en Europe, peuvent alors se rapprocher facilement des élites locales et même devenir des médiateurs dans les échanges entre ces pays et dans le processus de transfert des cultures. La librairie française, établie solidement en Europe, sert de canal important dans ce processus.

Les publications «russes» de ces périodiques suivent leur orientation générale: politique, littérature, librairie française. Les écrits des émigrés sont toujours marqués par les idées sur la Russie qui circulaient avant la Révolution, mais en même temps, leurs réflexions sur le progrès des Lumières sont confrontées à leur expérience des bouleversements politiques. Ils considèrent la Russie comme une puissance susceptible de rétablir l'ordre en France et en Europe. D'où l'image idéale d'Alexandre Souvorov, "Saint Souvorov », selon le mot du comte de Choiseul-Gouffier ${ }^{147}$ : on salue ses victoires, on le défend contre «des reproches de cruautés». En général, les sujets russes traités dans ces journaux concernent surtout la politique extérieure de l'Empire, ses forces militaires. Par contre, les renseignements sur la situation intérieure de la Russie, sont presque absents. Le Spectateur du Nord, un des plus importants journaux des émigrés qui donne une place large aux thèmes russes, y compris à la littérature, compte parmi ses collaborateurs Nicolas Karamzine, l'un des plus grands écrivains russes de l'époque. Le rédacteur, Amable de Baudus, manifeste sa sympathie pour la Russie. Plus tard, au temps de la Restauration, quand il est nommé par le duc de Richelieu à la tête du Bureau qui est chargé de la censure des journaux français et de l'examen des ouvrages politiques, il a toujours cette réputation de russophile. Ainsi, un des informateurs du ministre de la Police baron Claude Philibert-Edouard Mounier, Thomas Elder Darby, qui était alors attaché à l'ambassade d'Angleterre à Paris, écrit le 23 octobre 1821 : «On dit que M. Bodus exerce la censure des journaux sous une influence tellement Russe qu'il n'a pas voulu laisser publier l'éloignement de M. Nesselrode des affaires, quoique des lettres parvenues à la fois des trois villes, Augsbourg, Pétersbourg et Odessa aient transmis cette nouvelle au Bureau du Journal des Débats » ${ }^{148}$.

Au tournant du XVIII ${ }^{\mathrm{e}}$ et XIX ${ }^{\mathrm{e}}$ siècle, le Spectateur du Nord dirigé par Baudus peint des portraits favorables des monarques russes. On garde la mémoire de Pierre $\mathrm{I}^{\mathrm{er}}$, le tsarréformateur, le véritable héros du siècle des Lumières. On défend la personnalité de Paul $\mathrm{I}^{\mathrm{e}}$, même après sa mort, et on dénonce le ton démagogue de Charles Masson qui, dans ses mémoires, " insulte » cet empereur ${ }^{149}$. On place ses espérances dans le nouvel empereur Alexandre $\mathrm{I}^{\mathrm{er}}$, qui déclare le retour aux traditions de sa grand-mère. On se souvient de Catherine II elle-même, de son malheureux époux Pierre III. Néanmoins, les pages du Spectateur portent un regard plutôt critique sur l'impératrice, défini probablement par la position de Paul I ${ }^{\mathrm{er}}$.

\footnotetext{
147 Владимир А. Сомов, «Русская переписка графа Шуазель-Гуффье», “Беседа любителей русского слова": 200 лет, [Vladimir A. Somov, "La correspondance russe du comte de Choiseul-Gouffier ", "Conférence des amateurs de la langue russe": 20o ans], Saint-Pétersbourg, 2013, p. 168.

${ }^{148}$ Archives nationales, AN 234/AP. Je remercie Madame Florence de Baudus pour cette précieuse information.

${ }^{149}$ Le Spectateur du Nord, 1801, novembre, p. 262.
} 
Les journalistes émigrés sont étroitement liés à la Russie, ils en reçoivent régulièrement un soutien financier et politique et ils sont reconnaissants à la cour russe. Plusieurs d'entre eux trouvent refuge en Russie, ils entrent même au service impérial. Les royalistes ont des connaissances importantes dans le milieu diplomatique, dans la société russe, et ils sont bien informés. L'éditeur de plusieurs journaux des émigrés, Pierre François Fauche, se rend en visite dans l'Empire plus d'une fois. Il est lié à des libraires de Saint-Pétersbourg et de Moscou. La presse francophone «allemande » influence directement la presse francophone « russe », qui reste toujours l'affaire des émigrés. De leur côté, les pouvoirs russes surveillent régulièrement ces périodiques et contrôlent l'image de la Russie diffusée en Occident.

En Russie même, le Journal Littéraire de Saint-Pétersbourg, publié régulièrement pendant deux ans, est le périodique francophone le plus stable du XVIII ${ }^{\mathrm{e}}$ siècle. Dès le début, il est favorisé par les pouvoirs, parce que toute la revue a contribué à former l'image de l'Empire comme d'un pays où la littérature, le théâtre, les beaux-arts fleurissent, où les lettres françaises sont cultivées, où la librairie française se développe. Le cas d'un périodique officieux, le Journal du Nord, montre bien que la cour de SaintPétersbourg, qui sait apprécier l'importance de la presse francophone, a recours à l'expérience des émigrés, pour défendre les intérêts politiques de l'Empire. 